\title{
Efficient Synthesis and Functionalization of 3-Bromo Naphtho[2,3b]thiophene
}

\author{
Emily K. Burke, $\dagger^{\mathrm{a}}$ Erin N. Welsh, $\uparrow^{\mathrm{a}}$ Katherine N. Robertson, ${ }^{\mathrm{b}}$ and Alexander W. H. Speed ${ }^{* a}$ \\ ${ }^{*}$ Correspondance should be directed to aspeed@dal.ca \\ tThese authors contributed equally.
}

\begin{abstract}
Naphtho[2,3b]thiophene is a linear sulfur containing polycyclic aromatic hydrocarbon. Naphtho[2,3b]thiophene and its derivatives are commonly accessed by a Bradsher cyclization. Synthesis of the Bradsher cyclization substrate typically requires harsh conditions, including several oxidation state changes. Here we report an improved, multigram synthesis of 3bromonaphtho[ $2,3 b]$ thiophene, exploiting a copper-catalyzed cross coupling to prepare the Bradsher substrate in 3 steps from commercial materials while minimizing redox reactions. Modification of the naphthothiophene scaffold in the 3-position has not previously been reported. In this work, the 3-bromonaphthothiophene is further functionalized via lithium-halogen exchange, with the key finding being a specific order of addition in lithiation is required to avoid undesired rearrangement reactions. A small yet versatile set of derivatives, including a naphthothiophene-containing chiral amine are prepared.
\end{abstract}

\section{Introduction}

In the course of our research program involving chiral amines, we wished to synthesize amines containing a naphtho[2,3b]thiophene group. Naphthothiophenes are isomers of dibenzothiophene, and have found use in molecular electronic applications, including field-effect transistors, ${ }^{1}$ and medicinal chemistry. ${ }^{2}$ The linear isomer, naphtho[2,3b]thiophene (hereafter abbreviated naphthothiophene) is not currently commercially available. The first synthesis of naphthothiophene was reported by Carruthers (Scheme 1, equation 1). ${ }^{3}$ The key step involved zinc mediated reduction of quinone 1a, with a yield of naphthothiophene 2a on the order of $1 \%$. Carruthers pointed out that naophthothiophene is more stable than anthracene towards dearomatization of the central ring, by either Diels-Alder reaction, or oxidation, implying replacement of anthracenyl groups with naphthothienyl groups may impart added stability to molecules. ${ }^{4}$ A similar route by MacDowell and co-workers involved access to the naphthothiophene core by Friedel-Crafts acylation (Scheme 1 equation 2). ${ }^{5}$ MacDowell's synthesis began by addition of 3-thienyllithium to 2bromobenzaldehyde, followed by reduction of the doubly-benzylic alcohol product 3 to afford benzyl-thiophene derivative 4 . Carbonation of the Grignard reagent derived from $\mathbf{4}$ afforded acid 5a, which was cyclized via intramolecular Friedel-Crafts acylation with the corresponding acyl chloride, affording hydroxy naphthothiophene $\mathbf{2 b}$. Castle and co-workers developed a similar route to $\mathbf{2 a}$, avoiding formation of a hydroxy-naphthothiophene by changing the oxidation state of the cyclization partner to an aldehyde in 6a (Scheme 1, equation 3). ${ }^{6}$ Such intramolecular Friedel-Crafts cyclizations with carbonyls are commonly termed Bradsher cyclizations. ${ }^{7}$ 
(1)
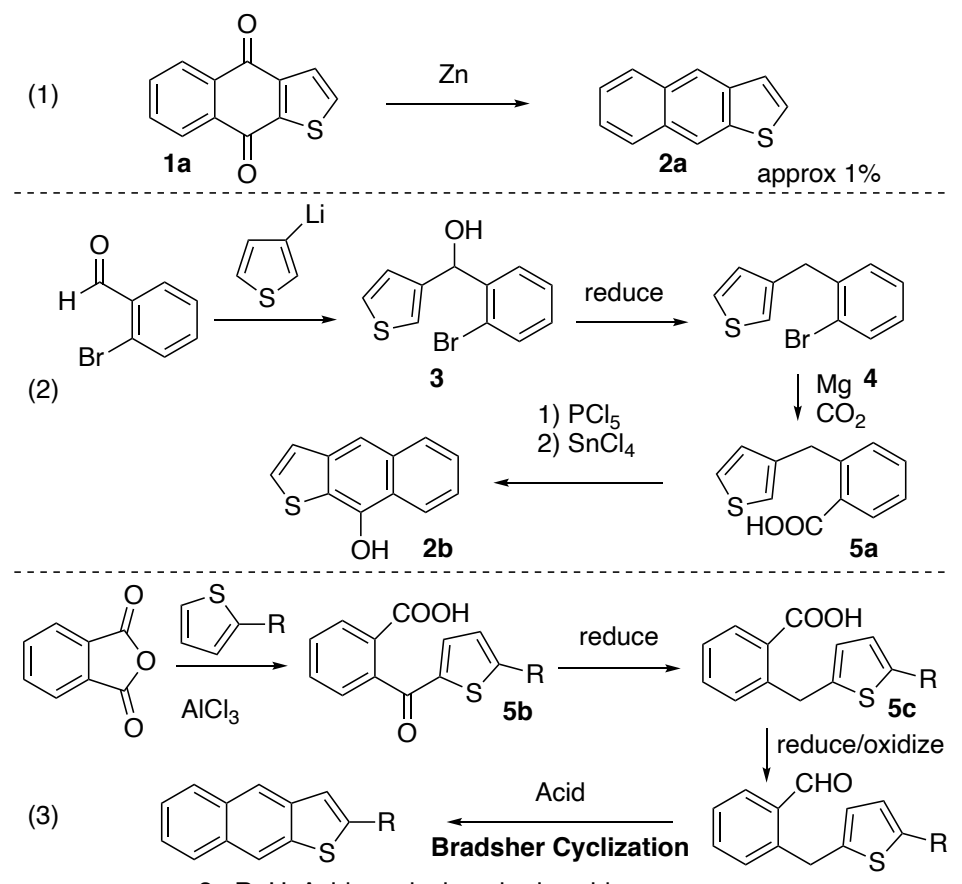

2a $\mathrm{R}=\mathrm{H}$, Acid = polyphosphoric acid

$6 a$ 2c $\mathrm{R}=2$-thienyl, Acid $=\mathrm{BF}_{3} \mathrm{OEt}_{2}$

(4)

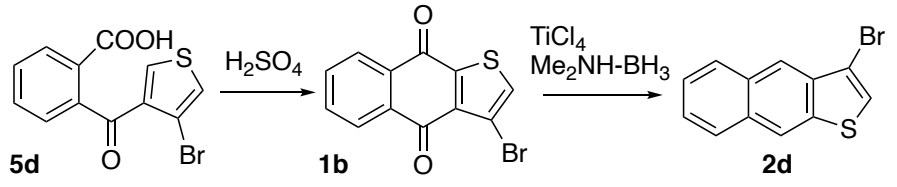

Scheme 1. Pertinent Synthetic Routes to Naphthothiophene and Derivatives

In Castle's Bradsher substrate, the cyclization occurred on the 3-position of thiophenes 6a. Related intermediates were also accessed by Mohanakrishnan and co-workers. ${ }^{8}$ Both groups used a similar strategy to access that substrate, which was different than that of MacDowell, and reminiscent of Carruthers' earlier work. ${ }^{3 \mathrm{~B}}$ Friedel-Crafts reaction between a thiophene and phthalic anhydride afforded keto-acid $\mathbf{5 b}$ (Scheme 1, equation 3). The ketone could be selectively reduced via Clemmensen reduction to afford acid 5c. Transformation of $\mathbf{5 c}$ to $\mathbf{6 a}$ was accomplished by reduction to the alcohol, and reoxidation to the aldehyde. Castle and coworkers employed poly-phosphoric acid for the Bradsher reaction to afford naphthothiophene 2a, while Mohanakrishnan and coworkers subsequently employed more conveniently handled $\mathrm{BF}_{3}$ etherate in the Bradsher cyclization. ${ }^{8}$ In this work a 2-thienyl substituent in the 2-position of the thiophene withstood the synthesis to afford 2-(2-thienyl)-naphthothiophene 2c. Mohanakrishnan subsequently showed $\mathrm{HI} /$ red phosphorus could effect both the reduction and cyclization step. ${ }^{9}$ Further studies by Mohanakrishnan and co-workers also showed that malonylidene units could be used as an aldehyde surrogate in comparable chemistry with very electron rich arenes, leading to elimination of a malonate rather than water. ${ }^{10}$ In another approach, Steinmetz and co-workers accessed 3-bromonaphthothiophene 2d via a more successful modification of the Carruthers method (Scheme 1, equation 4). ${ }^{11}$ Keto-acid 5d was accessed by Friedel-Crafts chemistry and thiophene bromination, and subsequently cyclized to quinone $\mathbf{1 b}$ employing sulfuric acid. Reduction of quinone $\mathbf{1 b}$ to $\mathbf{2 d}$ in the presence of a titanium tetrachloride/amine-borane mixture occurred with a synthetically useful yield. While overreduction did occur, the overreduction product could be converted to 2d with DDQ. Loss of the bromide was not reported under these conditions. A completely different approach to 3-iodonaphthothiophene that did not involve Bradsher cyclization was reported by Tovar and co-workers, ${ }^{12}$ employing methodology developed by Larock and coworkers, ${ }^{13}$ and elaborated by Takimiya and co-workers. ${ }^{14}$ While this synthesis was relatively efficient it used high loadings of palladium, rendering scale-up expensive. 


\section{Results and discussion}

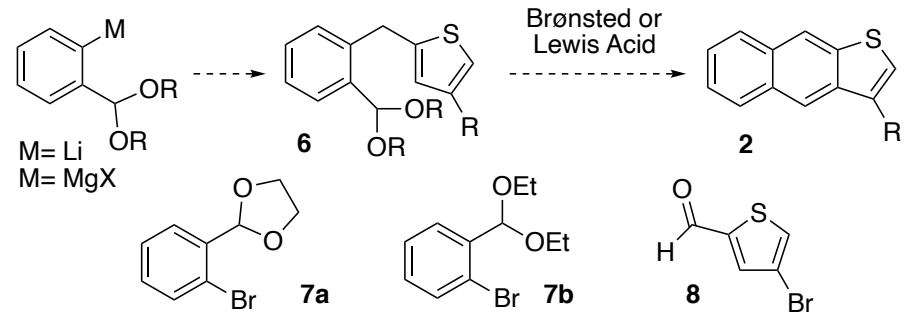

Scheme 2. Envisioned Bradsher approach to 3-bromonaphthothiophene, and key starting materials

We wished to synthesize either parent naphthothiophene $\mathbf{2 a}$ or 3-bromonaphthothiophene $\mathbf{2 d}$ as substrates for further derivatization. In considering practical scale-up of the reaction, we wished to avoid the phthalic anhydride Friedel-Crafts step used in earlier routes because of negative experiences with copious amounts of aluminate waste necessitating a difficult filtration. The subsequent ketone reduction also presented practicality or safety issues. The harsh Clemmensen conditions required amalgamation, and the use of $\mathrm{I}_{2} /$ red phosphorus presented supply/regulatory issues in our jurisdiction. The Bradsher cyclizations reported by Castle and Mohanakrishnan to prepare thiophene-containing acenes were particularly effective, because of the electron-rich nature of thiophenes. We wished to keep the efficient Bradsher reaction as a key step. Since Steinmetz did not employ a Bradsher cyclization with an aldehyde to access $\mathbf{2 d},{ }^{11}$ we remained uncertain if bromo-substitution on the thiophene, which may withdraw electron density would perturb the outcome of the reaction. We recognized that MacDowell's approach would represent a more efficient way of accessing the Bradsher cyclization substrate than the thiophene phthaloylation used by Castle and Mohanakrishnan, if oxidation state changes could be minimized. Accordingly, we targeted preparation of Bradsher substrates from an organometallic already containing a latent aldehyde, so that the carbonation and the two subsequent oxidation state changes originally used by MacDowell could be avoided (Scheme 2). Bromo-acetal 7a can be prepared in one step from 2-bromobenzaldehyde, while bromoacetal $\mathbf{7 b}$ and bromo-thiophenecarbaldehyde $\mathbf{8}$ are commercially available. We recognized the potential of these key starting materials for an improved route. Literature precedent suggests that Bradsher cyclization can directly occur from acetals, meaning that hydrolysis of the acetal may be unnecessary, further improving efficiency. ${ }^{15}$

(1)

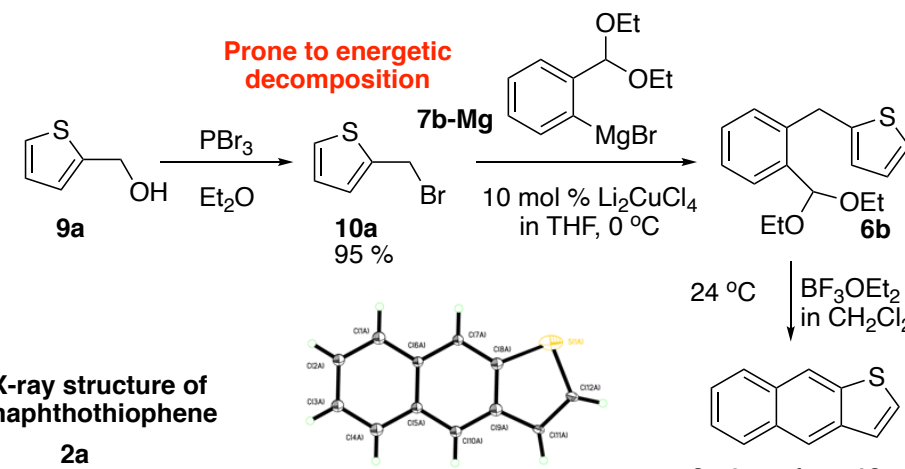

2a

2a $65 \%$ from $10 a$

(2)
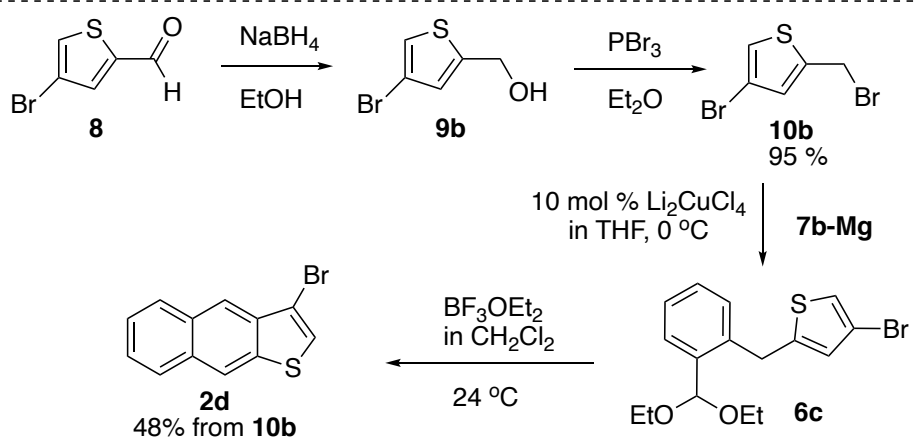

Scheme 3. Realized Bradsher routes to naphthothiophene and 3-bromonaphthothiophene

We decided to prepare a Bradsher cyclization substrate via direct alkylation of the Grignard reagent derived from commercially available bromoacetal $\mathbf{7 b}$ with thienylmethyl bromide 10a, rather than making 7a (Scheme 3, equation 1 ). ${ }^{16}$ Bromide 10a is accessible in 1 step from commercial flavoring ingredient thienylmethanol 9a. ${ }^{17}$ This alkylation procedure avoids the oxidation state changes shown in previous routes to naphthothiophenes shown in Scheme 1. Grignard reagent $\mathbf{7 b}-\mathbf{M g}$ was formed from $\mathbf{7 b}$ 
and magnesium turnings. This Grignard reagent was added to a mixture of thienylmethyl bromide 10a and 10 mol \% lithium tetrachlorocuprate in THF at $0{ }^{\circ} \mathrm{C}$ to afford coupling product $\mathbf{6 b} .{ }^{18}$ Addition of $\mathrm{BF}_{3}-\mathrm{OEt}_{2}$ to a dichloromethane solution of unpurified 6b resulted in Bradsher cyclization to naphthothiophene 2a directly from the acetal. Naphthothiophene $\mathbf{2 a}$ was readily purified by column chromatography. Crystals of $\mathbf{2 a}$ were grown by evaporation from an ethereal solution, and while somewhat disordered, allowed satisfactory X-ray analysis, providing the first crystal structure of 2a. This sequence afforded naphthothiophene $\mathbf{2 a}$ on gram scale in $65 \%$ yield over three steps from 2-thienylmethanol 9a with only one purification. This result showed that direct alkylation of an acetal-containing Grignard reagent was more efficient than McDowell's approach involving addition to an aldehyde, reduction, organometallic carbonation, and redox reactions of the resulting acid. The reaction directly afforded the methylene connection in the correct oxidation state between the aryl group and thiophene, with the latent aldehyde already in place, meaning that carbonation and redox state changes could be avoided. While this procedure represents a more efficient synthesis in terms of step and purification count than existing syntheses of $\mathbf{2 a}$, a practical safety issue became apparent during scale-up when we observed that intermediate 10a was not a stable compound. A five-gram sample of 10a underwent vigorous decomposition at room temperature. The unobserved decomposition ejected the stopper and charred material from the flask. The remaining black solid was not soluble in any common laboratory solvents, precluding further analysis. Many electron-rich alkoxybenzyl halides are unstable or are only stable in solution. ${ }^{19}$ We assume the decomposition noted in our sample of 10a was a consequence of an exothermic ring-alkylation polymerization, undergoing autocatalysis with release of $\mathrm{HBr}$. Due to this potential safety issue, we discontinued studies toward naphthothiophene $\mathbf{2 a}$ by this route.

We returned to a synthesis of derivative $\mathbf{2 d}$ via an analogous route to that employed for $\mathbf{2 a}$, but where the bromine was pre-installed on the desired position of the thiophene with the anticipation that the bromide would stabilize the corresponding intermediate by slowing ring-alkylation polymerization (Scheme 3, Equation 2). Alcohol 9b, prepared by sodium borohydride reduction of $\mathbf{8}$, was brominated with $\mathrm{PBr}_{3}$ in diethyl ether. Thienyl bromide $\mathbf{1 0 b}$ solidified upon cooling, and we never observed decomposition of this compound in the solid state, though we were cautious to avoid heating the compound during its preparation. In analogy to 10a lithium tetrachlorocuprate-mediated coupling with Grignard reagent $\mathbf{7 b} \mathbf{\mathbf { M g }}$ gave $\mathbf{6 c}$. Attempts to purify $\mathbf{6 c}$ by column chromatography before the Bradsher cyclization did not result in improved purity and only detracted from the yield in the subsequent step. Unpurified 6c underwent Bradsher cyclization mediated by boron trifluoride etherate to form 2d in $48 \%$ yield from 10b, indicating minimal perturbation from the bromide to the cyclization reaction. Use of an excess of Grignard reagent in the previous step is important to ensure complete consumption of $\mathbf{1 0 b}$ since $\mathbf{1 0 b}$ is challenging to separate from naphthothiophene $\mathbf{2 d}$ by column chromatography, and was observed to release $\mathrm{HBr}$, which decomposed impure samples of $\mathbf{2 d}$. Only one positional isomer of bromide 2d was observed after the Bradsher cyclization. Bromonaphthothiophene 2d was prepared on a 2.5 gram scale over four steps from aldehyde $\mathbf{8}$ by this route, with only one chromatographic purification required. For our purposes, this result compared favourably in terms of yield, ease of work-up, and reagent availability to the existing route to $\mathbf{2 d} .^{11}$

With an improved route to 3-bromonaphthothiophene in place, a family of derivatives of naphthothiophene were prepared. Reports of functionalization of naphthothiophenes are sparse, with Castle and co-workers having reported acylation in the 2 position, ${ }^{6}$ and Steinmetz and co-workers reporting lithiation of the 2 position. ${ }^{11}$ None of these reports involve functionalization of the more hindered and less-acidic 3-position. ${ }^{20} \mathrm{We}$ initially targeted a boronic ester (11a, Scheme 4), which represents a versatile handle for further functionalization.

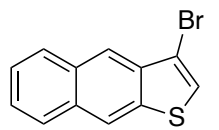

2d

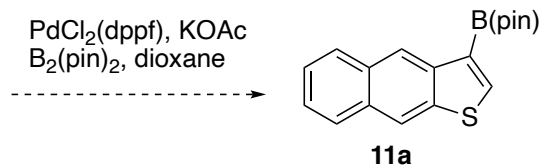

$11 \mathrm{a}$

Observed products (other unidentified products were also present)

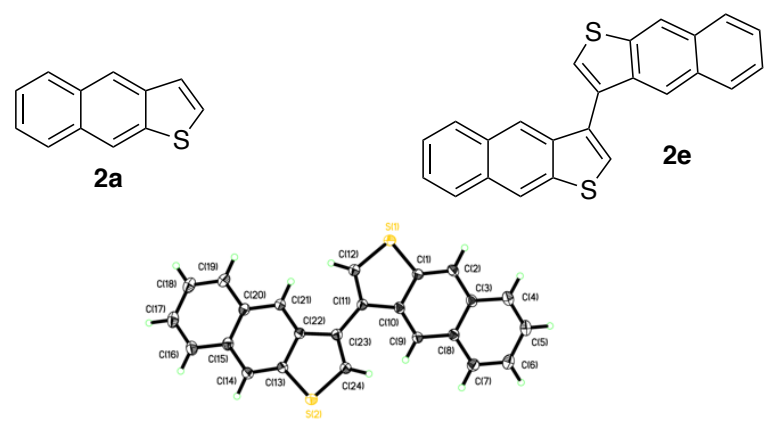

Structure of $2 e$

Scheme 4. Attempted Miyaura Borylation 
We initially attempted a Miyaura borylation due to the mildness of the reported conditions (Scheme 4). Unfortunately, exposure of the bromide to $\mathrm{PdCl}_{2}$ (dppf), sodium acetate, and $\mathrm{B}_{2}(\text { pin })_{2}$ in refluxing dioxane gave a complex mixture of products. Two products were identified. Naphthothiophene 2a was recovered. Another highly UV active product was observed by TLC and was separated by chromatography. Crystallization and X-ray analysis showed it was the 3,3' bi-naphthothiophene (Scheme 4, compound 2e). Interestingly, Miyaura borylation on 3-bromobenzothiophene proceeded uneventfully in our hands under the same conditions, ${ }^{21}$ implying that the dimerization reactivity might be a property of the specific heterocycle.

We instead decided to target functionalization by lithiation/quench. ${ }^{22}$ We had some trepidation about the stability of 3lithionaphthothiophene $2 \mathbf{f}$ (Scheme 5). ${ }^{23}$ To the best of our knowledge, lithiation of naphthothiophene has not been previously reported. As the best approximation found in literature, 3-lithiobenzothiophene 12a has been reported to undergo both isomerization to more stable 2-lithiobenzothiophene $\mathbf{1 2 b}$ and ring opening to $\mathbf{1 2 c}$ upon warming (Scheme 5, equation 1). Upon adding n-BuLi to a solution of $\mathbf{2 d}$ at $-78{ }^{\circ} \mathrm{C}$ in THF, an immediate colour change was observed. Isopropoxy B(pin) was added after 10 minutes. Unfortunately, this reaction resulted in a relatively complex mixture of products that could not be completely analyzed.

Potential decomposition of 3-lithiobenzothiophene

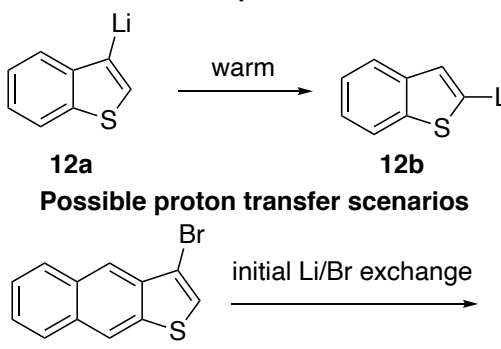

2d

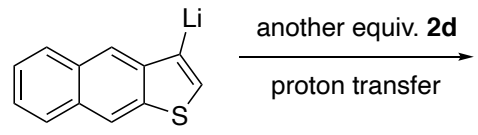

$2 f$<smiles>c1ccc2cc3sccc3cc2c1</smiles>

2a

Observed products with iPrOB(pin) quench<smiles>c1ccc2cc3sccc3cc2c1</smiles>

$2 a$<smiles>Brc1sc2cc3ccccc3cc2c1Br</smiles>

11b<smiles>C#Cc1ccccc1S[AlH2]</smiles>

12c<smiles>Clc1csc2cc3ccccc3cc12</smiles>

$2 f$<smiles>Clc1sc2cc3ccccc3cc2c1Br</smiles>

$2 \mathrm{~g}$

Thermodynamic equilibriation:
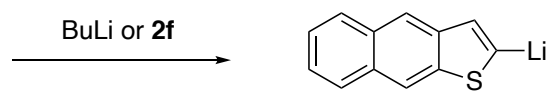

2h

\section{Scheme 5. Initial Lithiation Attempt of 3-bromonaphthothiophene}

Both parent naphthothiophene 2a, and multiple boron containing compounds were observed, however chromatographic separation was not possible in our hands precluding complete characterization. A hint as to what happened was obtained when a single crystal was serendipitously obtained by evaporation of a solution of the product mixture. While the crystal was highly disordered, X-ray crystallography revealed the presence of a bromine in the 3 position and $\mathrm{HB}$ (pin) group in the 2-position corresponding to structure 11b. Furthermore, occupancy of less than $100 \%$ was observed for the $\mathrm{Br}$, suggesting the presence of some material with a $\mathrm{B}$ (pin) at the 2 position, and a $\mathrm{H}$ at the 3 position. Coupled with the presence of parent naphthothiophene 2a, we speculated that the order of addition meant that in addition to the expected lithiation (Equation 2) rapid proton transfer occurred between organolithium and non-lithiated 2d (Equation 3), during the course of the addition of the n-BuLi. Also as 2a was formed, it could undergo lithiation in the most acidic 2-position, either from $\mathrm{n}-\mathrm{BuLi}$ or organolithium $\mathbf{2 f}$ (Equation 4). Such equilibration phenomena have been reported for the lithiation of 3-bromothiophenes. ${ }^{24}$ While a complete scenario of the reactions occurring upon addition of $n-$ butyllithium to 3-bromonaphthothiophene $\mathbf{2 d}$ could not be detailed due to a paucity of data, it was evident this set of conditions would not lead to a viable functionalization reaction. A possible solution was envisioned in the form of inverting the order of addition. We added a solution of bromide $2 \mathbf{d}$ in THF to an excess of $\mathrm{n}-\mathrm{BuLi}$ in solution in THF at $-84{ }^{\circ} \mathrm{C}$, followed by boron 
quench in an attempt to circumvent this problem (Scheme 6, Equation 1). Upon following this procedure, arylpinacolboronate 11a was obtained in $57 \%$ yield as one regioisomer after quench and purification. The connectivity was confirmed by X-ray crystallography of a single crystal of 11a grown by evaporation of a diethyl ether solution. A similar procedure where DMF was employed to quench the organolithium afforded aldehyde 11c in comparable yield (58\%), however minor inseparable impurities $(<10 \%$ by NMR) were observed in this product.

We then turned our attention to the preparation of chiral amines containing the naphthothiophene moiety. Imine 13, derived from propionaldehyde and Ellman auxiliary was added to freshly prepared 3-lithionaphthothiophene $\mathbf{2 f}$. $^{25}$ This protocol cleanly afforded 14 as a separable mixture of diastereomers. X-ray quality crystals of both diastereomers 14a and 14b were grown by cooling saturated diethyl ether solutions of the isolated diasteromers. In addition to correlating relative configuration to NMR spectra, which will be of use to anyone working in this field, these structures, shown in Scheme 6, confirmed that the products of the Ellman addition were epimers at the newly created stereocentre, rather than regioisomers arising from rearrangement of the lithiated heterocycles. Deprotection of the major diastereomer with ethereal $\mathrm{HCl}$ followed by basification afforded chiral amine $\mathbf{1 5}$. We will note to anybody interested in pursuing work with these compounds that an alternate bond connection order, where an Ellman auxiliary was condensed with aldehyde 11c was less convergent and provided less clean material upon both condensation of the auxiliary, and addition of ethyl Grignards. Other attempts to perform the Ellman chemistry with a methyl rather than ethyl sidechain resulted in inseparable diastereomers, an observation also made in our earlier work with a dibenzothiophene-containing chiral amine, where ethyl sidechains were more tractable than methyl sidechains. ${ }^{26}$
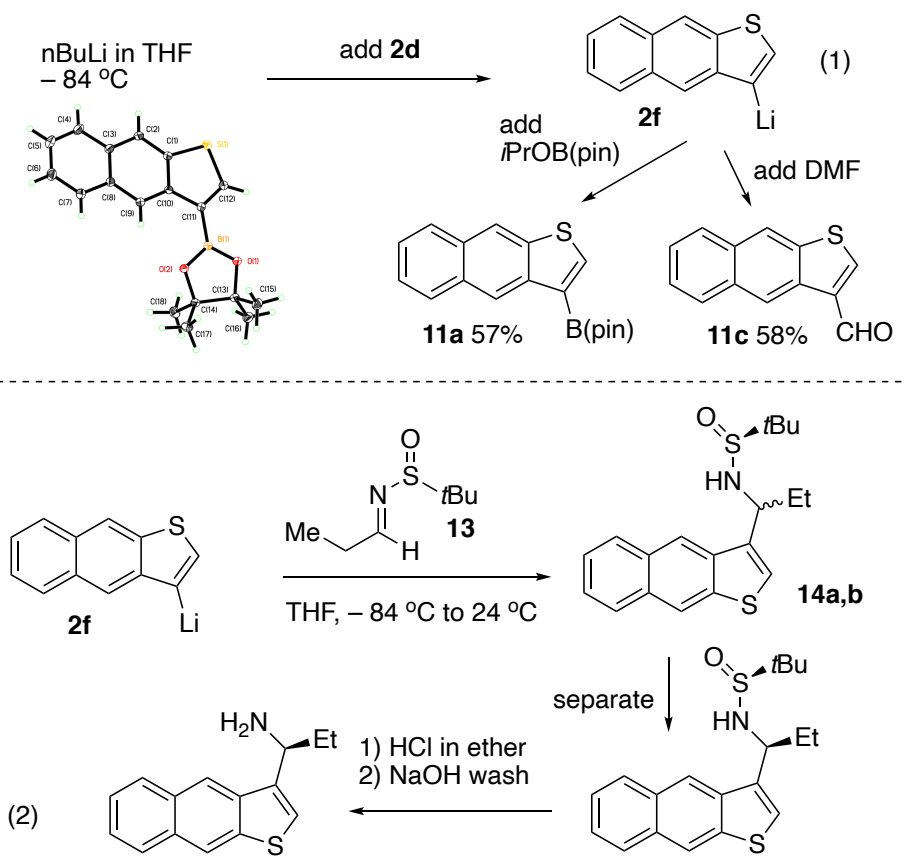

15

14a Major diastereomer
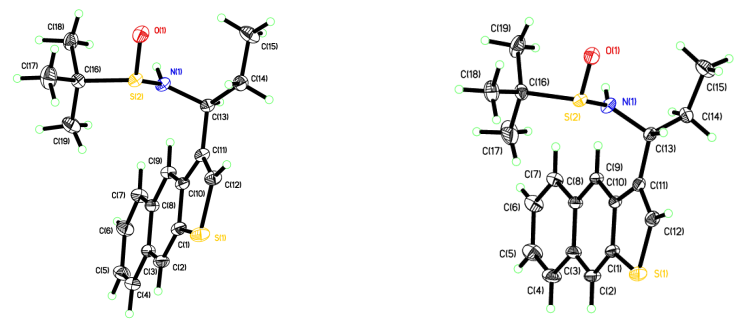

Major Diastereomer 14a

Minor Diastereomer 14b

\section{Scheme 6. Successful functionalization of 3-bromonaphthothiophene}

\section{Conclusions}

In conclusion, we developed an approach to naphthothiophenes using an efficient Bradsher cyclization, while improving the synthesis of the Bradsher substrate versus previous routes by leveraging copper-mediated coupling of a Grignard reagent containing a latent aldehyde to minimize oxidation state changes. This strategy avoids harsh reagents and is the first use of this variety of 
organo-copper coupling in naphthothiophene synthesis. This has resulted in an efficient route to 3-bromonaphthothiophene $\mathbf{2 d}$ Functionalization of the naphthothiophene proved challenging, with a Miyura borylation giving an undesired outcome, however we show that lithiation of 3-bromonaphthothiophene $\mathbf{2 d}$ is feasible. Care regarding the addition order was needed, with addition of the aryl bromide to the alkyllithium being required to avoid undesirable isomerization. We showed how 3-bromonaphthothiophene $\mathbf{2 d}$ can be transformed into an enantiopure amine 15 using Ellman auxiliary methodology. A specific ethyl side-chain, and addition of the lithiated arene to the imine of propionaldehyde were required for clean reaction outcome, and practical separation of

diastereomers. Further exploration of the applications of naphthothiophene containing molecules are in progress and will be reported in due course. ${ }^{27}$

\section{Conflicts of interest}

There are no conflicts to declare

\section{Acknowledgements}

This work was supported by NSERC of Canada through a Discovery Grant (2017-04297), an Idea to Innovation Grant (I2IPJ 523283-18), and the CREATE Training Program in BioActives (510963). Labrador's Post-Secondary Student Support Program and the Nova Scotia Graduate Scholarship are thanked for E.N.W.'s graduate funding.

Dr. Michael Lumsden and Mr. Xiao Feng (Dalhousie University) are thanked for assistance with NMR spectroscopy and mass spectrometry, respectively. Dr. Travis Lundrigan is thanked for the preparation of a batch of $\mathbf{9 b}$ and 14.

${ }^{1}$ A) Yamashita, T. "Bis-naphthothiophene derivative and electric field effect transistor" JP2010053094A. B) M. Mamada, H. Katagiri, M. Mizukami, K. Honda, T Minamiki, R. Teraoka, T. Uemura, S. Tokito, ACS Appl. Mater. Interfaces 2013, 5, 9670 .

${ }^{2}$ A) B. P. Das, R. T. Cunningham, D. W. Boykin, J. Med. Chem. 1973, 16, 1361. B) A. Basoglu, S. Dirkmann, N Zahedi Golpayegani, S. Vortherms, J. Tentrop, D. Nowottnik, H. Prinz, R. Froehlich, K. Mueller, Eur. J. Med. Chem. 2017, 134, 119.

${ }^{3}$ A) W. Carruthers, J. R. Crowder, J. Chem. Soc., 1957, 1932.

B) W. Carruthers, A. G. Douglas, J. Hill, J. Chem. Soc., 1962, 704.

${ }^{4}$ W. Carruthers, J. Chem. Soc., 1963, 4477

${ }^{5}$ D. W. H. MacDowell, J. C. Wisowaty, J. Org. Chem., 1971, 36, 3999.

${ }^{6}$ M. L. Tedjamulia, Y. Tominaga, R. N. Castle, M. L. Lee, J. Heterocyclic Chem., 1983, $20,1143$.

${ }^{7}$ A) C. K. Bradsher, J. Am. Chem. Soc., 1940, 62, 486. B) C. K. Bradsher, Chem. Rev., 1987, 87, 1277. C) A. Bodzioch, E. Kowalska, J. Skalik, P. Bałczewski, Chem. Heterocycl. Compd. 2017, 53, 11.

${ }^{8}$ S. M. Rafiq, R. Sivasakthikumaran, J. Karunakaran, A. K. Mohanakrishnan, Eur. J. Org. Chem. $2015,5099$.

${ }^{9}$ S. M. Rafiq, A. K. Mohanakrishnan, Synlett, 2017, 28, 362.

${ }^{10}$ V. Dhayalan, A. K. Mohanakrishnan, Synth. Commun. 2012, 42, 2149.

${ }^{11}$ L. Li, G. N. Ndzeidze, M. G. Steinmetz, Tetrahedron, 2019, 75, 70.

12 R. E. Messersmith, M. A. Siegler, J. D. Tovar, Synlett, 2018, 29, 2499.

13 D. Yue, R. C. Larock, J. Org. Chem., 2002, 67, 1905.

${ }^{14}$ A) K. Niimi, E. Miyazaki, I. Osaka, K. Takimiya, Synthesis, 2012, 44, 2102.

${ }_{15}$ P. Bałczewski, M. Koprowski, A. Bodzioch, B. Marciniak, E. Różycka-Sokołowska, J. Org. Chem. 2006, 71, 2899.

${ }^{16}$ F. A. Vingiello, S.-G. Quo, J. Sheridan, J. Org. Chem. 1961, 26, 3202.

${ }^{17}$ M. Leolukman, P. Paoprasert, Y. Wang, V. Makhija, D. J. McGee, P. Gopalan, Macromol. $2008,41,4651$.

${ }^{18}$ M. Tamura, J. K. Kochi, J. Organomet. Chem. 1972, 42, 205.

${ }^{19}$ P. T. Brian, P. Musau, Indones. J. Chem., 2016, 16, 53.

${ }^{20}$ Lithiation of 3-iodonaphthothiophene and independent preparation of 11a were reported by Haley and co-workers during the course of our work: G. I. Warren, J. E. Barker, L. N. Zakharov, M. M. Haley, Org. Lett. $2021,23,5012$. Spectral data for 11a were in agreement.

${ }^{21}$ Z. Li, J. Zhang, W. Zhang, L. Guo, J. Huang, G. Yu, M. S. Wong, Org. Electron. 2016, $32,1566$.

${ }^{22}$ H. Nakagawa, S. Kawai, T. Nakashima, T. Kawai, Org. Lett. 2009, 11, 1475.

${ }^{23}$ R. P. Dickinson, B. Iddon, J. Chem. Soc. C., 1970, 2592.

${ }^{24}$ A) X. Wu, T.-A. Chen, L. Zhu, R. D. Rieke, Tet. Lett. 1994, 35, 3673. B) M. Sonoda, S. Kinoshita, T. Luu, H. Fukuda, K. Miki, R. Umeda, Y. Tobe, Synth. Commun. 2009, 39, 3315. 
${ }^{25}$ T. Ishida, R. Kobayashi, T. Yamada, Org. Lett. 2014, 16, 2430.

${ }^{26}$ E. N. Welsh, K. N. Robertson, A. W. H. Speed, Org. Biomol. Chem. 2021, 19, 2000.

${ }^{27}$ Preliminary aspects of this work, including the preparation of 2a, 2d, 11a and 11c were reported in E. N. Welsh, E. K. Burke, K. N. Robertson, A. W. H. Speed, ChemRxiv. 2019 


\title{
Efficient Synthesis and Functionalization of 3-Bromo Naphtho[2,3b]thiophene
}

\author{
Emily K. Burke ${ }^{\dagger a}$, Erin N. Welsh ${ }^{\dagger a}$, Katherine N. Robertson ${ }^{\mathrm{b}}$, Alexander W. H. Speed ${ }^{\mathrm{a} *}$ \\ aDepartment of Chemistry, Dalhousie University, Halifax, Nova Scotia, Canada B3H 4R2 \\ ${ }^{b}$ Department of Chemistry, Saint Mary's University, Halifax, Nova Scotia, Canada B3H 3C3 \\ *Correspondance should be directed to aspeed@dal.ca \\ These authors contributed equally.
}

1. General Experimental Considerations...............................................

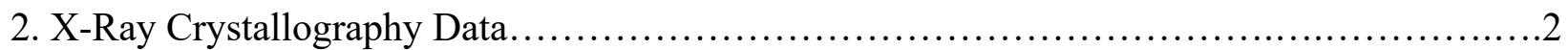

3. Synthetic Procedures and Characterization Data..........................................

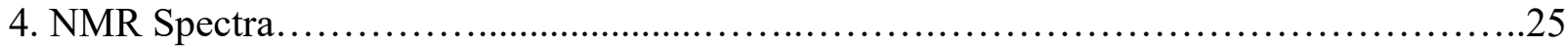




\section{General Experimental Considerations}

Reactions were run under nitrogen, using oven-dried glassware unless otherwise specified. ${ }^{1} \mathrm{H}$, ${ }^{13} \mathrm{C}$, and ${ }^{11} \mathrm{~B}$ NMR data were collected at $300 \mathrm{~K}$ on a Bruker AV-500 NMR spectrometer. ${ }^{1} \mathrm{H}$ NMR spectra are referenced to residual non-deuterated NMR solvent $\left(\mathrm{CHCl}_{3}=7.26 \mathrm{ppm}\right) .{ }^{13} \mathrm{C} \mathrm{NMR}$ spectra are referenced to the central $\mathrm{CDCl}_{3}$ peak $(77.16 \mathrm{ppm})$. Mass spectrometric data were acquired by Mr. Xiao Feng (Mass Spectrometry Laboratory, Dalhousie University).

\section{Solvents}

Diethyl ether was purchased as anhydrous ACS reagent grade, $>99.0 \%$ stabilized by BHT in $1 \mathrm{~L}$ metal cans from Aldrich.

Dichloromethane (ACS grade) was purchased from Fisher. Dichloromethane for reactions was distilled from calcium hydride immediately before use, while no purification was carried out on dichloromethane used for extractive work-ups.

Deuterochloroform for NMR of complexes was stored over activated $3 \AA$ molecular sieves, but otherwise used as received. Deuterochloroform for substrates and products was used as received.

Tetrahydrofuran was purchased from Aldrich in a Sure/seal ${ }^{\circledR}$ bottle (anhydrous, $>99.9 \%$, inhibitor free, catalogue number 401757). Tetrahydrofuran was used directly from this bottle for Grignard reactions and lithiations.

\section{Reagents}

2-Bromobenzaldehyde diethyl acetal, n-Butyllithium, dimethyl formamide, magnesium turnings, phosphorus tribromide, and propionaldehyde were purchased from Aldrich and used directly as received.

4-Bromothiophene-2-carboxaldehyde and isopropoxy $\mathbf{B}($ pin) were purchased from Oakwood Chemical and used directly as received.

Ellman Sulfinimide Auxiliary was purchased from Oakwood Chemical and configuration was verified by measurement of optical rotation. 


\section{X-Ray Crystallography Data}

The crystal chosen was attached to the tip of a MicroLoop with Paratone-N oil. Measurements were made on a Bruker D8 VENTURE diffractometer equipped with a PHOTON III CMOS detector using monochromated Mo K $\alpha$ radiation $(\lambda=0.71073 \AA)$ from an Incoatec micro-focus sealed tube at the temperature indicated, 100 to $150 \mathrm{~K}$ [1]. The initial orientation and unit cell were indexed using a least-squares analysis of the reflections collected from a $180^{\circ}$ phi-scan, 2 seconds per frame and $1^{\circ}$ per frame. For data collection, a strategy was calculated to maximize data completeness and multiplicity, in a reasonable amount of time, and then implemented using the Bruker Apex 3 software suite [1]. The crystal to detector distance was set to $4 \mathrm{~cm}$ and 15 second frames were collected unless otherwise stated. Cell refinement and data reduction were performed with the Bruker SAINT [2] software, which corrects for beam inhomogeneity, possible crystal decay, Lorentz and polarisation effects. A multi-scan absorption correction was applied (SADABS [3]). The structure was solved using SHELXT-2014 [4] and was refined using a full-matrix leastsquares method on $F^{2}$ with SHELXL-2018 [4]. The non-hydrogen atoms were refined either as part of a rigid group (see below) or anisotropically. The hydrogen atoms bonded to carbon were included at geometrically idealized positions and were not refined. The isotropic thermal parameters of these hydrogen atoms were fixed at $1.2 U_{\text {eq }}$ of the parent carbon atom or $1.5 U_{\text {eq }}$ for methyl hydrogens. All H(N) hydrogen atom positions were located in near final Fourier difference maps. They were allowed to refine isotropically and were not restrained in any way.

\section{Compound 2a}

The crystals supplied for this compound were in the form of very thin sheets. They did not diffract well at all, and it was very difficult to obtain a useable data set; many crystals were attempted with little success. Even with the chosen long frame times $(20 \mathrm{sec})$, very few reflections were obtained. These were weak and the resolution of the data set as a whole was poor. The data was cut off at a resolution of $0.83 \AA$ by adding a SHEL instruction to the refinement. This resulted in a number of checkcif alerts once the final refinement had been carried out. Level $\mathrm{C}$ alerts were obtained because of the High R1 Value, High wR2 Value and Poor Data / Parameter Ratio. The poor quality of the data set also resulted in the absolute structure not being reliably determined.

Because of the lack of data, a rigid group refinement was carried out for the naphthyl groups. This helped to increase the final data/parameter ratio to a barely acceptable 6.83 . The remaining atoms of the 5-membered rings containing the sulfur atoms were freely refined, but 1,2 and 1,3 distances were restrained to be equal using SADI commands. All of the carbon atoms were restrained to have similar thermal parameters, while $\mathrm{C} 11$ and $\mathrm{C} 12$ (individually) were restrained to have identical thermal parameters in each component of the disorder. The sulfur atoms in each part of the disorder were restrained to have similar thermal parameters and these were also restrained to have more isotropic geometries. After all of this the final data / restraints / parameters ratio was still poor $(1597 / 715 / 141)$ but there were no level A or B checkcif alerts.

The final model refined for this structure included a four part disorder of the entire molecule. In essence, the molecule could crystallize with the 5-membered ring containing the sulfur on either side of the central naphthyl rings, and in that 5-membered ring, the sulfur atom could be either up or down (bonded to different atoms of the naphthyl ring). The occupancies of these four 
components of the disorder were modelled and they refined to a ratio of $45.2: 18.7: 19.0: 17.1 \%$ with errors of roughly $1.5 \%$. The main component of the disorder is favoured (and it is shown in the figure in the main manuscript), while the other three components have a roughly equal distribution.

\section{Compound 2e}

Data collection with 30 second frames resulted in a data set that could be integrated to a resolution of $0.65 \AA$ resolution. All of this data was used in the final refinement.

\section{Compound 11a}

One reflection ( 336 ) was found to have poor agreement between $F_{\text {obs }}{ }^{2}$ and $F_{\text {calc }}{ }^{2}$ and was removed from the final refinement using an OMIT instruction. The data was integrated to $\theta_{\max }=39.66^{\circ}$ (0.56 Å resolution).

\section{Compound 11b}

The final model refined for this structure included a two part disorder of the 5-membered $\mathrm{C}_{4} \mathrm{SBr}$ ring. In essence, the molecule could crystallize with the sulfur center on either side of the ring, and the $\mathrm{C}-\mathrm{Br}$ group on the opposite side of the ring in each component. The occupancies of the two components of the disorder were modelled and they refined to a ratio of 91.88 and $8.12 \%$ with errors of $0.14 \%$. The main component of the disorder is favoured (and it is shown in the figure in the main manuscript). During the refinement, the disordered region of the molecule had to be heavily restrained. A SAME instruction was used to make the two 5-membered ring geometries similar. Additional 1,3 bond length restraints were added, as were restraints to make the thermal parameters of the ring atoms more similar.

A SHEL instruction was added to cut the data used in the refinement off at $\theta_{\max }=28.28^{\circ}$. Above this resolution $(0.83 \AA)$ the data collected was mostly noise.

\section{Compound 14a (major product)}

The crystal used for the data collection was not cut. When other crystals were cut, they shredded into long shards that were not suitable for data collection. To avoid this, a long needle/plate crystal was used without cutting it to fit it into the beam. However, this did result in a level C checkcif alert for the crystal being too long for the beam size. The other two dimensions were suitable.

The molecule was found to crystallize in the chiral space group $P 2_{1}$, with an $\mathrm{S}$ configuration at C13. The absolute structure of the molecule was reliably determined. Using the program Platon [5] the refined structure was calculated to have a Flack parameter of $-0.012(16)$, a Parsons 
parameter of $-0.003(16)$ and a Hooft parameter of 0.012(15). These values agree with the Parson's value calculated by the program SHELXL, -0.012(16) from 3921 selected quotients.

\section{Compound 14b (minor product)}

The molecule was found to crystallize in the chiral space group $P 2{ }_{1} 2_{1} 2_{1}$, with an R configuration at $\mathrm{C} 13$. The absolute structure of the molecule was reliably determined. Using the program Platon [5] the refined structure was calculated to have a Flack parameter of $-0.002(8)$, a Parsons parameter of $-0.001(7)$ and a Hooft parameter of $-0.007(7)$. These values agree with the Parson's value calculated by the program SHELXL, $-0.002(8)$ from 4386 selected quotients.

\section{References}

[1] APEX 3 (Bruker, 2018) Bruker AXS Inc., Madison, Wisconsin, USA.

[2] SAINT (Bruker, 2016) Bruker AXS Inc., Madison, Wisconsin, USA.

[3] SADABS (Bruker, 2016) Bruker AXS Inc., Madison, Wisconsin, USA.

[4] Sheldrick, G.M. (2015) Acta Cryst., A71, 3-8; Sheldrick, G.M. (2015) Acta Cryst., C71, 3-8.

[5] Spek, A.L. (2009) Acta Cryst., D65, 148-155. 
Table Sx: Crystal data and structure refinement details.

\begin{tabular}{|c|c|c|c|}
\hline Identification code & $2 a$ & $2 \mathrm{e}$ & $11 \mathrm{a}$ \\
\hline CCDC deposit number & 1958922 & 2116338 & 1999813 \\
\hline Temperature $(\mathrm{K})$ & 100 & 150 & 100 \\
\hline Empirical formula & $\mathrm{C}_{12} \mathrm{H}_{8} \mathrm{~S}$ & $\mathrm{C}_{24} \mathrm{H}_{14} \mathrm{~S}_{2}$ & $\mathrm{C}_{18} \mathrm{H}_{19} \mathrm{BO}_{2} \mathrm{~S}$ \\
\hline Formula weight & 184.24 & 366.47 & 310.20 \\
\hline Crystal system & Orthorhombic & Triclinic & Monoclinic \\
\hline Space group & $P 212121$ & $P-1$ & $P 21 / c$ \\
\hline \multirow[t]{6}{*}{ Unit cell dimensions $\left(\AA\right.$ and $\left.^{\circ}\right)$} & $a=5.8206(13)$ & $a=3.8894(4)$ & $a=5.9637(3)$ \\
\hline & $b=7.6166(16)$ & $b=14.4863(12)$ & $b=8.7167(4)$ \\
\hline & $c=19.769(4)$ & $c=15.6726(14)$ & $c=30.1381(15)$ \\
\hline & $\alpha=90$ & $\alpha=69.643(3)$ & $\alpha=90$ \\
\hline & $\beta=90$ & $\beta=86.726(3)$ & $\beta=90.395(2)$ \\
\hline & $\gamma=90$ & $\gamma=86.545(3)$ & $\gamma=90$ \\
\hline Volume $\left(\AA^{3}\right)$ & $876.4(3)$ & $825.77(13)$ & $1566.66(13)$ \\
\hline$Z$ & 4 & 2 & 4 \\
\hline Density (calculated, $\mathrm{Mg} / \mathrm{m}^{3}$ ) & 1.396 & 1.474 & 1.315 \\
\hline Absorption coefficient $\left(\mathrm{mm}^{-1}\right)$ & 0.308 & 0.327 & 0.210 \\
\hline $\mathrm{F}(000)$ & 384 & 380 & 656 \\
\hline Crystal size $\left(\mathrm{mm}^{3}\right)$ & $0.296 \times 0.226 \times 0.029$ & $0.202 \times 0.024 \times 0.019$ & $0.377 \times 0.344 \times 0.043$ \\
\hline Theta range of data $\left({ }^{\circ}\right)$ & 2.866 to 25.341 & 2.370 to 33.164 & 2.432 to 36.317 \\
\hline Index ranges $(h, k, l)$ & $-7 / 6,-9 / 9,-23 / 23$ & $-5 / 5,-22 / 22,-24 / 24$ & $-9 / 9,-14 / 14,-50 / 50$ \\
\hline Reflections collected & 19632 & 64074 & 60760 \\
\hline Independent reflections & 1597 & 6266 & 7579 \\
\hline $\mathrm{R}$ (int) & 0.1073 & 0.0568 & 0.0629 \\
\hline Completeness to $25.242^{\circ}(\%)$ & 99.9 & 99.99 & 99.8 \\
\hline Max. and min. transmission & 0.7477 and 0.5483 & 0.7465 and 0.7068 & 0.7478 and 0.5934 \\
\hline Data / restrains / parameters & $1597 / 715$ / 141 & $6266 / 0 / 235$ & 7579 / 0 / 203 \\
\hline Goodness-of-fit on $\mathrm{F}^{2}$ & 1.160 & 1.195 & 1.153 \\
\hline \multirow[t]{2}{*}{ Final $R$ indices $[I>2 \operatorname{sigma}(I)]$} & $\mathrm{R} 1=0.1360$ & $\mathrm{R} 1=0.0475$ & $\mathrm{R} 1=0.0586$ \\
\hline & $w R 2=0.2796$ & $\mathrm{wR} 2=0.1034$ & $\mathrm{wR} 2=0.1216$ \\
\hline \multirow[t]{2}{*}{$\mathrm{R}$ indices (all data) } & $\mathrm{R} 1=0.1511$ & $\mathrm{R} 1=0.0838$ & $\mathrm{R} 1=0.0721$ \\
\hline & $\mathrm{wR} 2=0.2871$ & $\mathrm{wR} 2=0.1350$ & $\mathrm{wR} 2=0.1270$ \\
\hline Absolute structure parameter & $0.41(12)$ & n.a. & n.a. \\
\hline Largest diff. peak and hole $\left(\mathrm{e} . \AA^{-3}\right)$ & 0.475 and -0.624 & 0.587 and -0.477 & 0.586 and -0.463 \\
\hline
\end{tabular}


Table Sx: Crystal data and structure refinement details (continued).

\begin{tabular}{|c|c|c|c|}
\hline Identification code & $11 \mathrm{~b}$ & 14a - major & $14 \mathrm{~b}$ - minor \\
\hline CCDC deposit number & 1999814 & 1999812 & 1999815 \\
\hline Temperature (K) & 100 & 125 & 125 \\
\hline Empirical formula & $\mathrm{C}_{18} \mathrm{H}_{18} \mathrm{BBrO}_{2} \mathrm{~S}$ & $\mathrm{C}_{19} \mathrm{H}_{23} \mathrm{NOS}_{2}$ & $\mathrm{C}_{19} \mathrm{H}_{23} \mathrm{NOS}_{2}$ \\
\hline Formula weight & 389.10 & 345.50 & 345.50 \\
\hline Crystal system & Monoclinic & Monoclinic & Orthorhombic \\
\hline Space group & $P 21_{1} / c$ & $P 2{ }_{1}$ & $P 2{ }_{1}{ }_{1}{ }_{1}$ \\
\hline \multirow[t]{6}{*}{ Unit cell dimensions $\left(\AA\right.$ and $\left.^{\circ}\right)$} & $a=9.4189(4)$ & $a=8.9768(4)$ & $a=8.9317(4)$ \\
\hline & $b=10.6805(5)$ & $b=9.4961(4)$ & $b=9.4815(4)$ \\
\hline & $c=16.5959(7)$ & $c=11.1085(5)$ & $c=21.8980(10)$ \\
\hline & $\alpha=90$ & $\alpha=90$ & $\alpha=90$ \\
\hline & $\beta=91.771(2)$ & $\beta=102.289(2)$ & $\beta=90$ \\
\hline & $\gamma=90$ & $\gamma=90$ & $\gamma=90$ \\
\hline Volume $\left(\AA^{3}\right)$ & $1668.73(13)$ & $925.24(7)$ & $1854.45(14)$ \\
\hline$Z$ & 4 & 2 & 4 \\
\hline Density (calculated, $\mathrm{Mg} / \mathrm{m}^{3}$ ) & 1.549 & 1.240 & 1.237 \\
\hline Absorption coefficient $\left(\mathrm{mm}^{-1}\right)$ & 2.594 & 0.292 & 0.291 \\
\hline$F(000)$ & 792 & 368 & 736 \\
\hline Crystal size $\left(\mathrm{mm}^{3}\right)$ & $0.180 \times 0.106 \times 0.075$ & $0.651 \times 0.103 \times 0.032$ & $0.374 \times 0.152 \times 0.098$ \\
\hline Theta range of data $\left({ }^{\circ}\right)$ & 2.268 to 28.282 & 2.657 to 39.384 & 2.341 to 39.380 \\
\hline Index ranges $(h, k, l)$ & $-12 / 12,-14 / 14,-22 / 22$ & $-15 / 15,-16 / 16,-19 / 19$ & $-15 / 15,-16 / 16,-37 / 38$ \\
\hline Reflections collected & 64929 & 41764 & 105907 \\
\hline Independent reflections & 4134 & 10545 & 10795 \\
\hline $\mathrm{R}$ (int) & 0.0414 & 0.0375 & 0.0335 \\
\hline Completeness to $25.242^{\circ}(\%)$ & 99.8 & 99.3 & 98.1 \\
\hline Max. and min. transmission & 0.7478 and 0.6629 & 0.7478 and 0.7004 & 0.7478 and 0.6954 \\
\hline Data / restrains / parameters & 4134 / 158 / 267 & $10545 / 1 / 216$ & $10795 / 0 / 216$ \\
\hline Goodness-of-fit on $\mathrm{F}^{2}$ & 1.081 & 1.049 & 1.063 \\
\hline \multirow[t]{2}{*}{ Final $R$ indices $[\mathrm{I}>2 \operatorname{sigma}(\mathrm{I})]$} & $\mathrm{R} 1=0.0315$ & $\mathrm{R} 1=0.0342$ & $\mathrm{R} 1=0.0276$ \\
\hline & $w R 2=0.0883$ & $\mathrm{wR} 2=0.0774$ & $\mathrm{wR} 2=0.0718$ \\
\hline \multirow[t]{2}{*}{$\mathrm{R}$ indices (all data) } & $\mathrm{R} 1=0.0325$ & $\mathrm{R} 1=0.0445$ & $\mathrm{R} 1=0.0305$ \\
\hline & $\mathrm{wR} 2=0.0889$ & $\mathrm{wR} 2=0.0839$ & $\mathrm{wR} 2=0.0736$ \\
\hline Absolute structure parameter & n.a. & $-0.012(16)$ & $-0.002(8)$ \\
\hline Largest diff. peak and hole $\left(\mathrm{e} . \AA^{-3}\right)$ & 0.627 and -0.858 & 0.370 and -0.376 & 0.318 and -0.269 \\
\hline
\end{tabular}




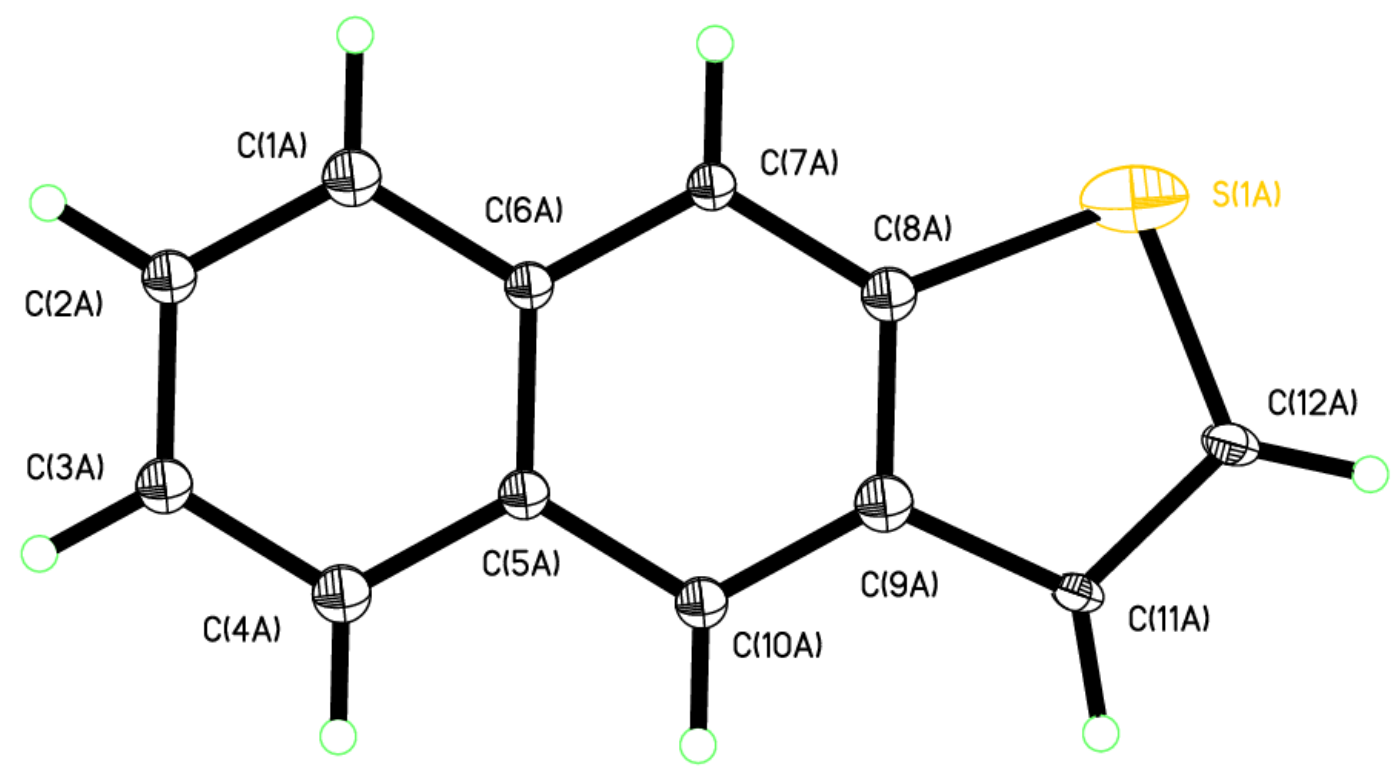

Structure of compound 2a showing only the main component of the 4-part disordered model. Thermal ellipsoids have been drawn at the 50\% probability level. Hydrogen atoms have not been labelled.

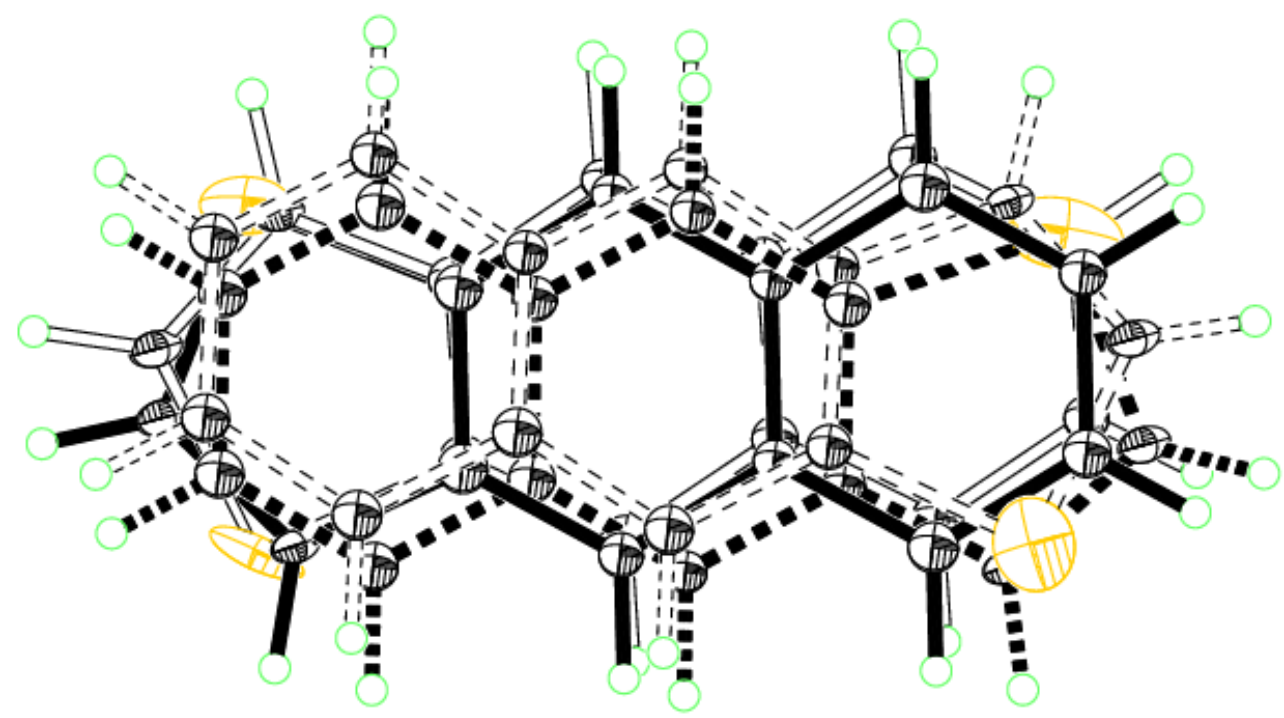

Structure of compound 2a showing all components of the 4-part disordered model. Thermal ellipsoids have been drawn at the $50 \%$ probability level. 

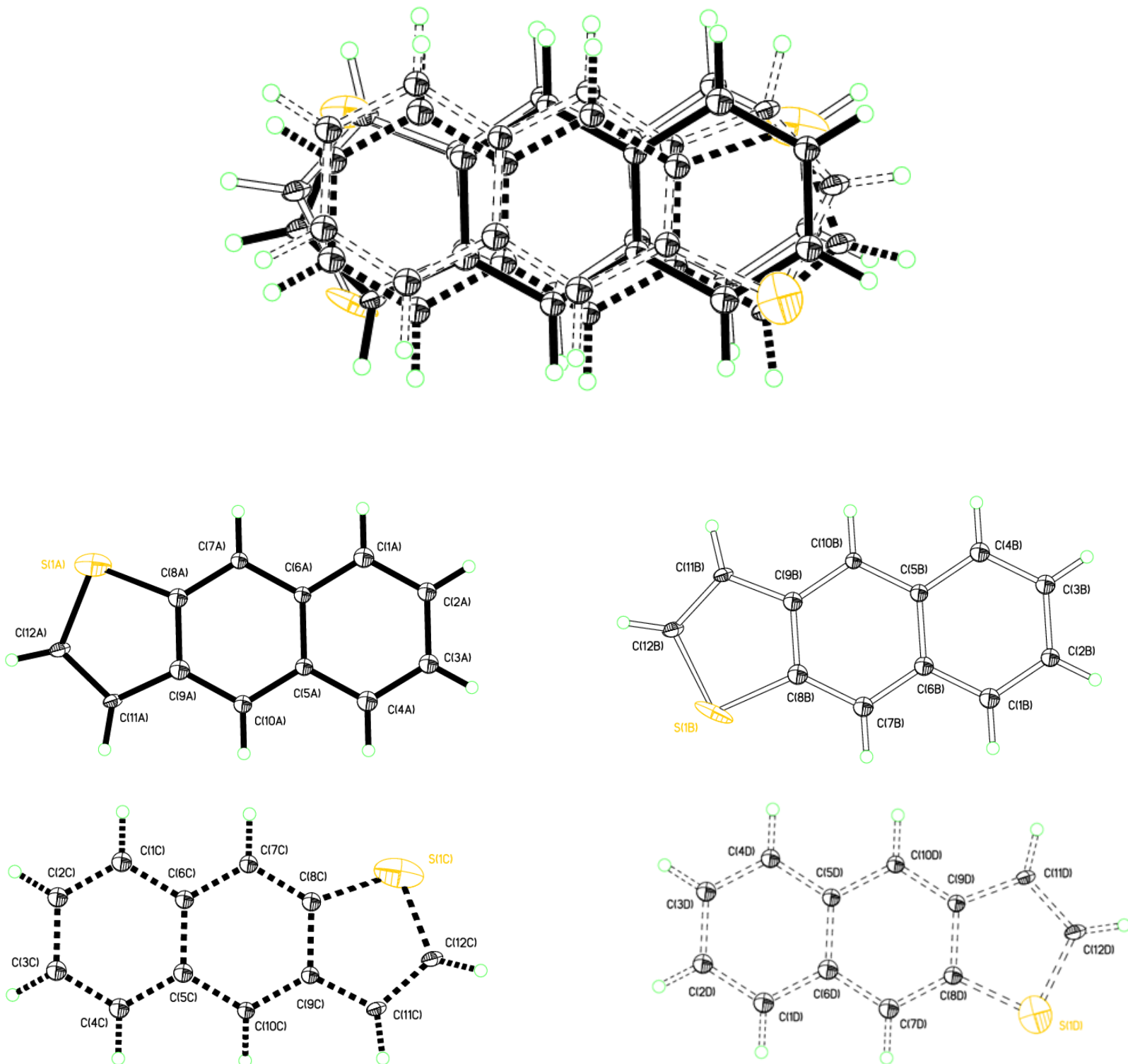

Structure of compound 2a showing all components of the 4-part disordered model (top). In the four lower diagrams each of the four individual components are shown. Thermal ellipsoids have been drawn at the $50 \%$ probability level. The heavy atoms have been labelled in the individual diagrams. 


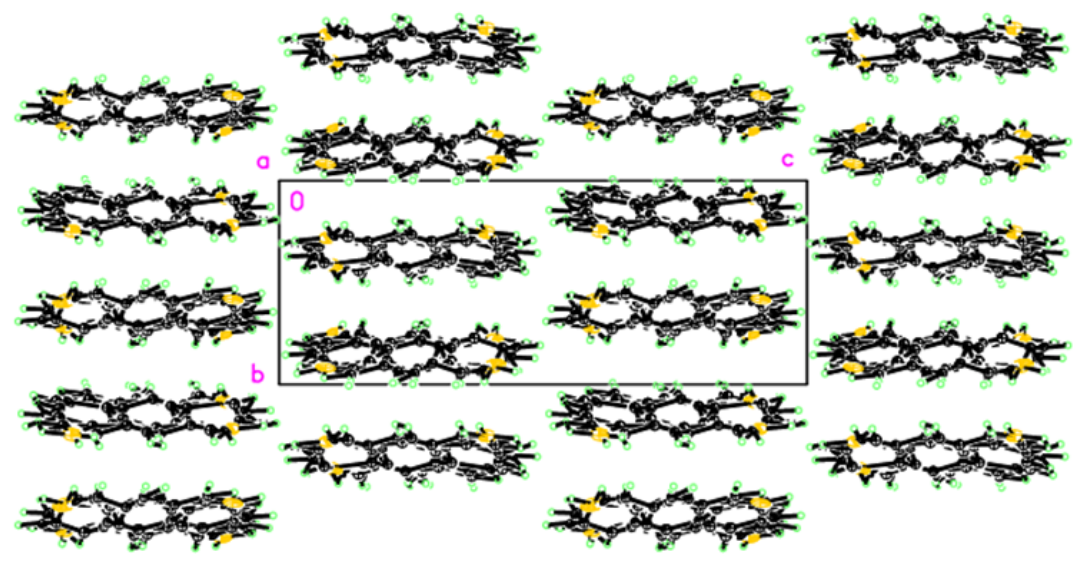

Packing diagram of compound 2a viewed down the $X$-axis.

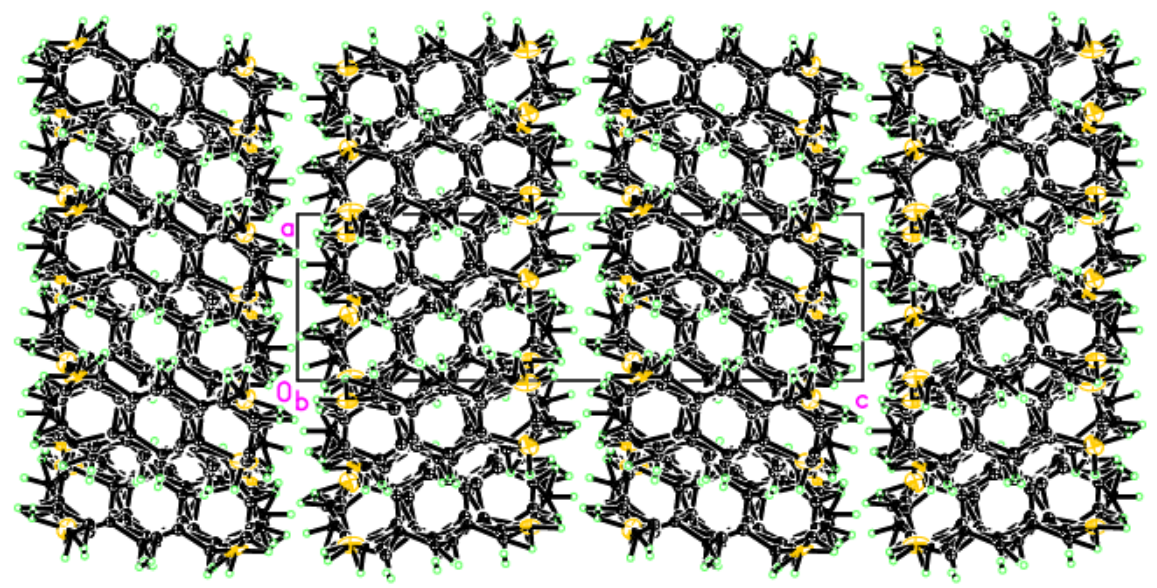

Packing diagram of compound 2a viewed down the $Y$-axis.

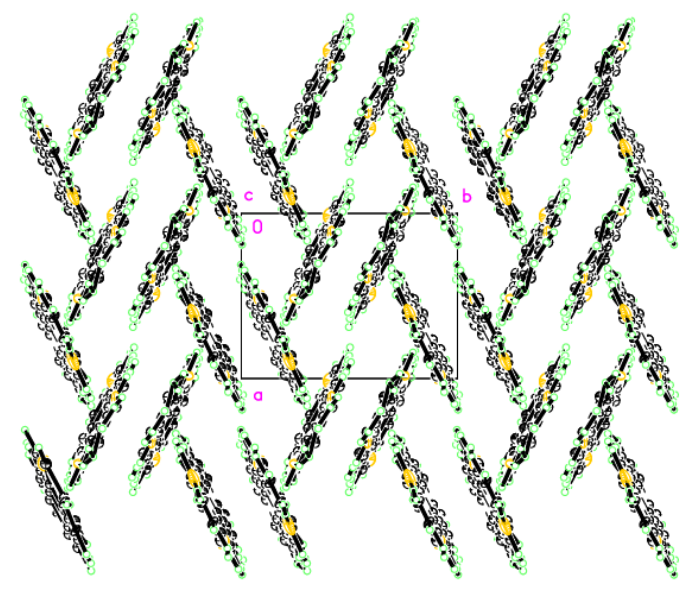

Packing diagram of compound 2a viewed down the $Z$-axis. 


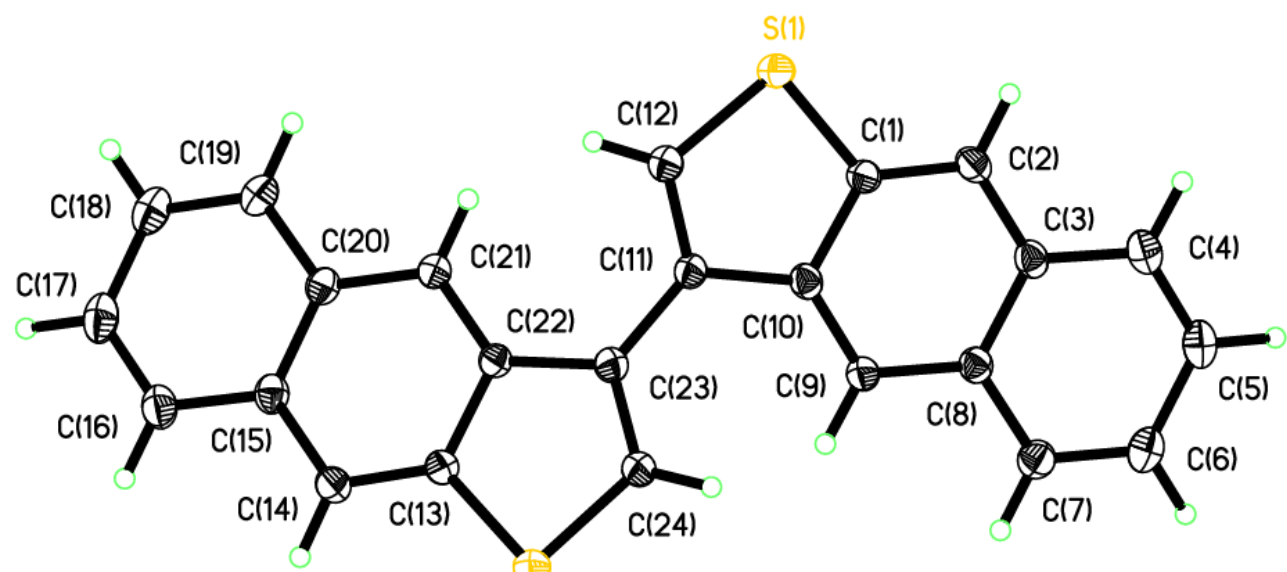

Structure of compound 2e. Thermal ellipsoids are drawn at the $50 \%$ probability level. Hydrogen atoms have not been labelled.

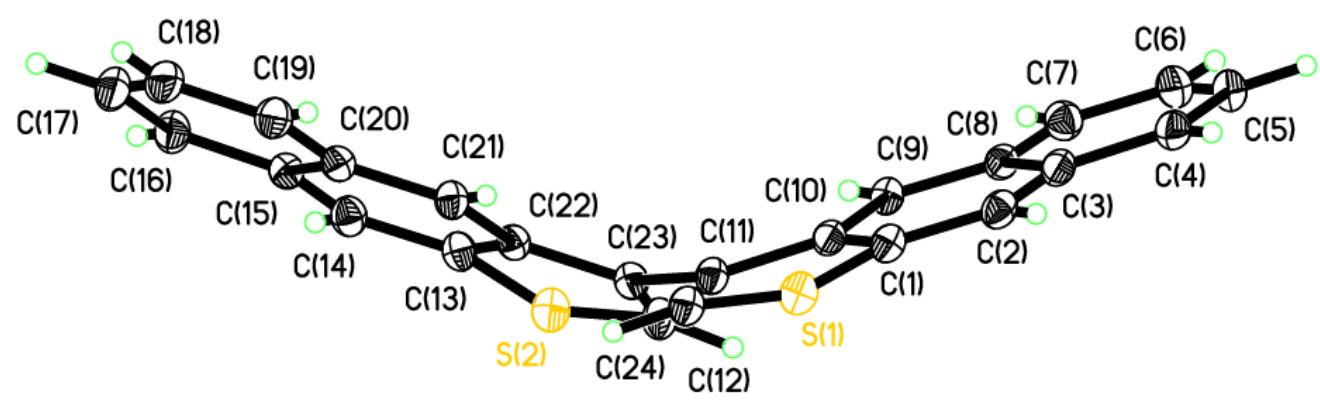

Side view of the structure of compound $\mathbf{2 e}$, rotated by $90^{\circ}$ relative to the first view above. Thermal ellipsoids are drawn at the $50 \%$ probability level. Hydrogen atoms have not been labelled.

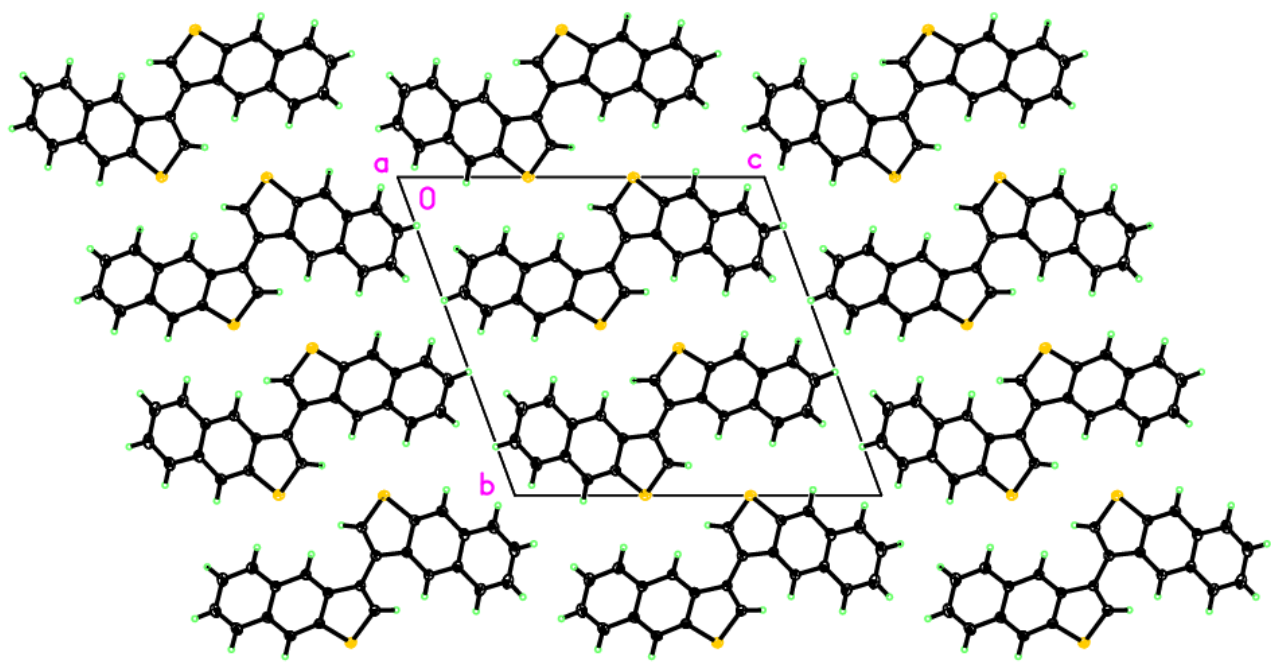

Packing diagram for compound 2e viewed down the $X$-axis. 


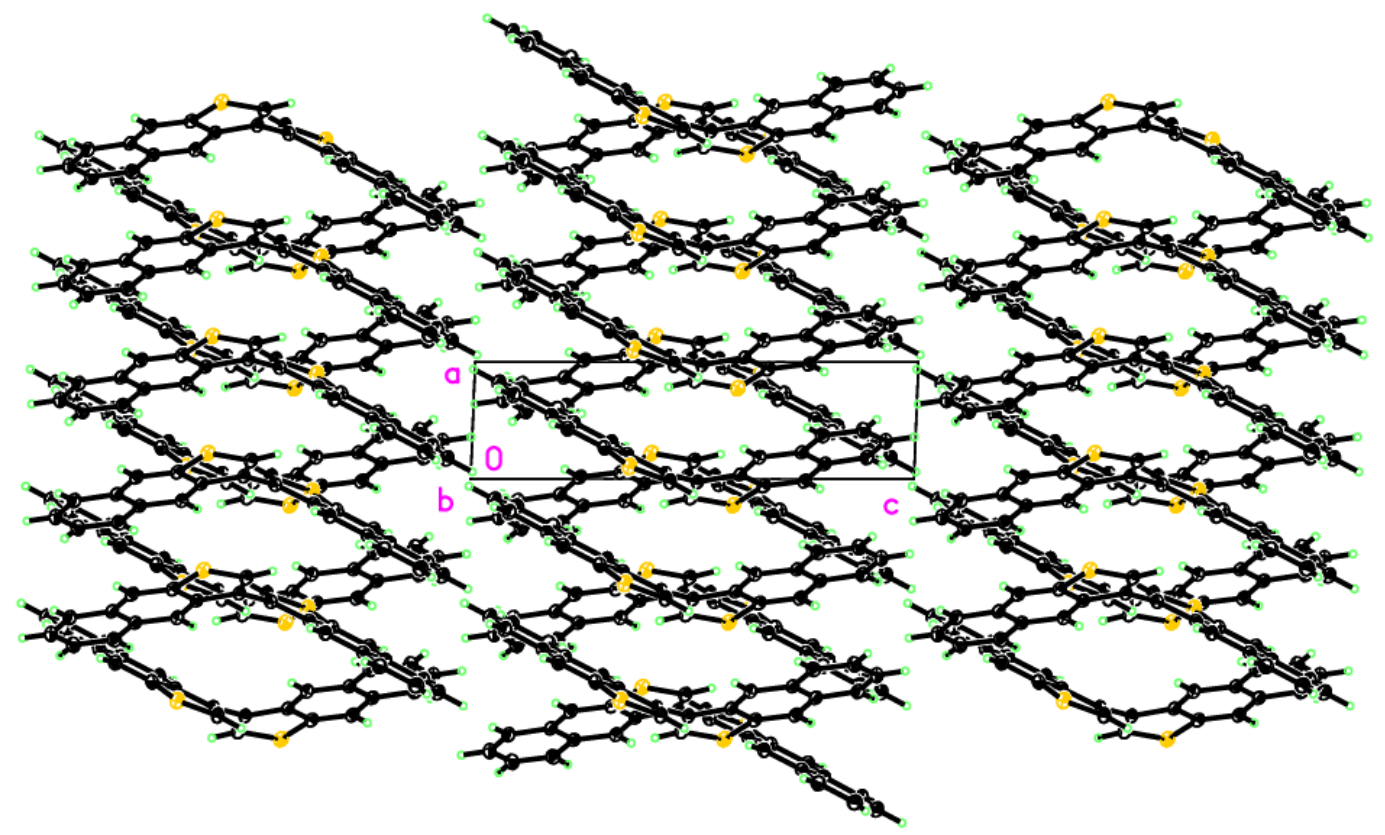

Packing diagram for compound $\mathbf{2 e}$ viewed down the $Y$-axis.

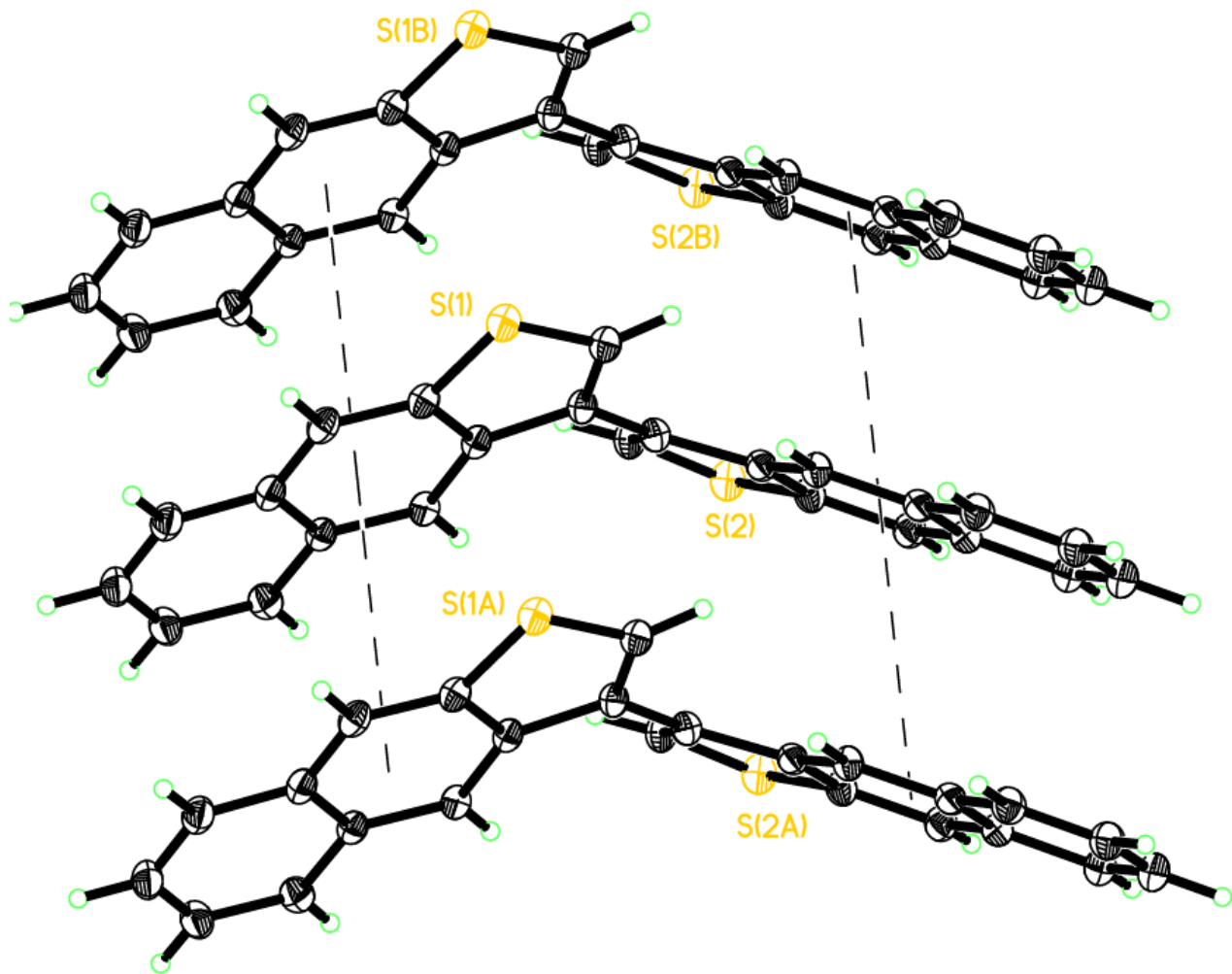

Stacking contacts in the compound 2e. Dashed lines join the centroids of the naphthothiophene groups. The molecules above and below the central molecule are generated by the symmetry operations $(x+1, y, z)$ and $(x-1, y, z)$ respectively. 


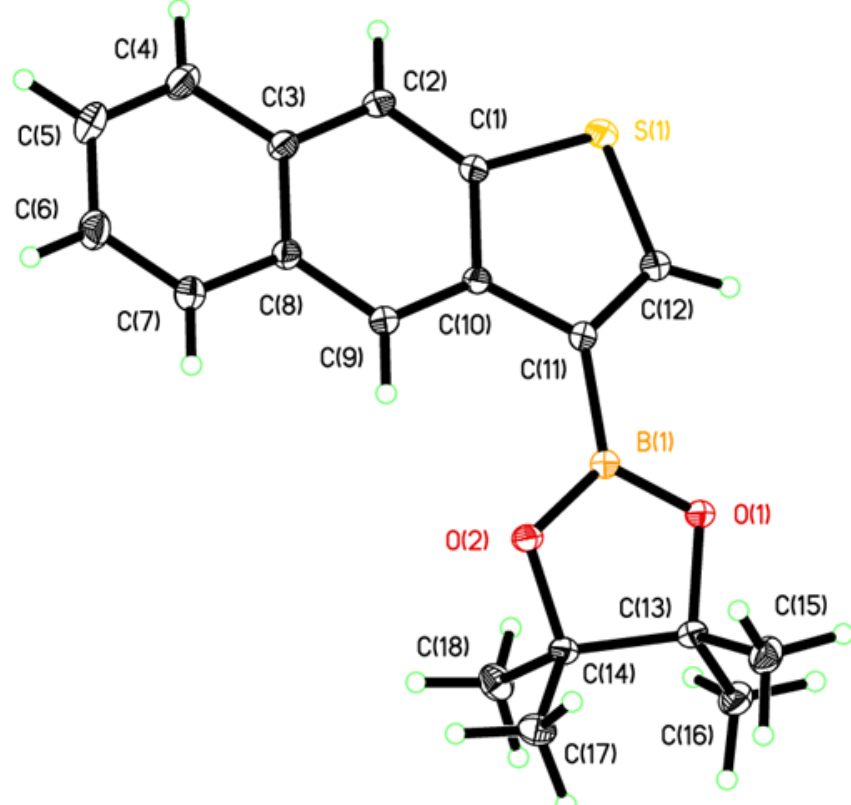

Structure of compound 11a. Thermal ellipsoids have been drawn at the 50\% probability level. Hydrogen atoms have not been labelled.

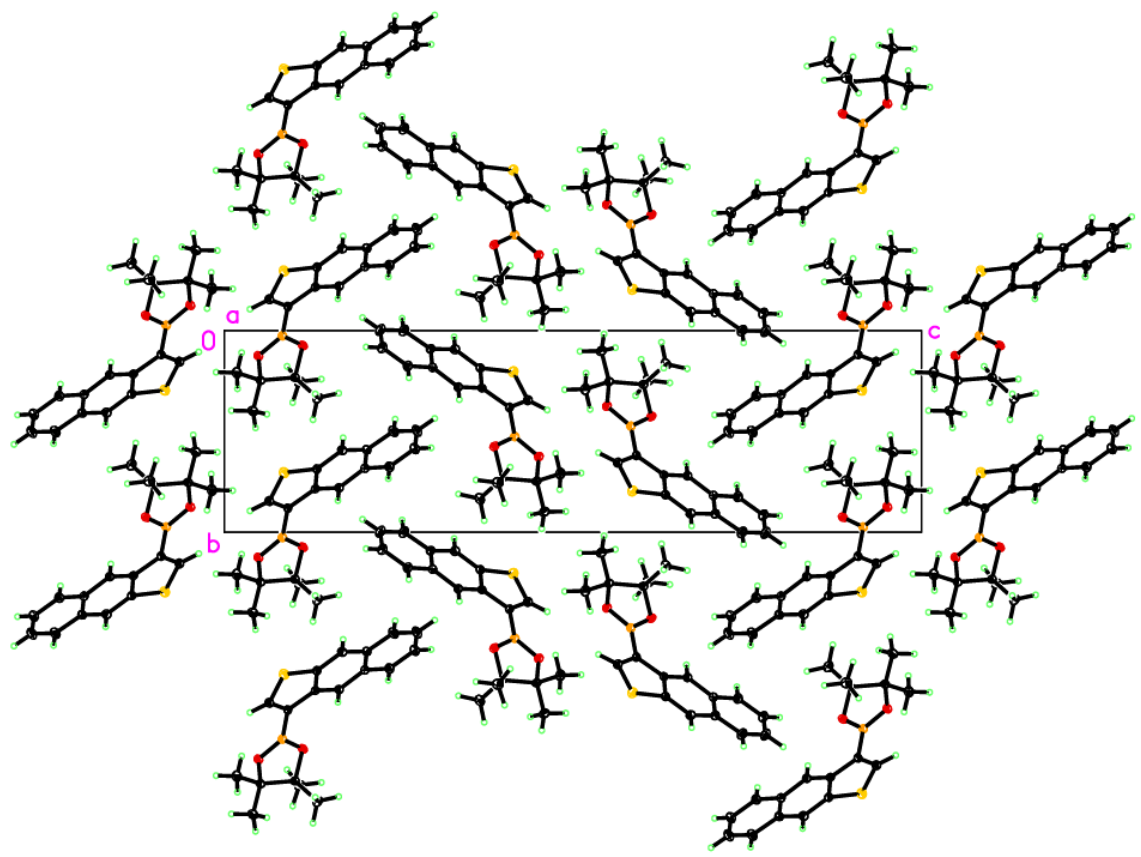

Packing diagram for compound 11a viewed down the $X$-axis. 


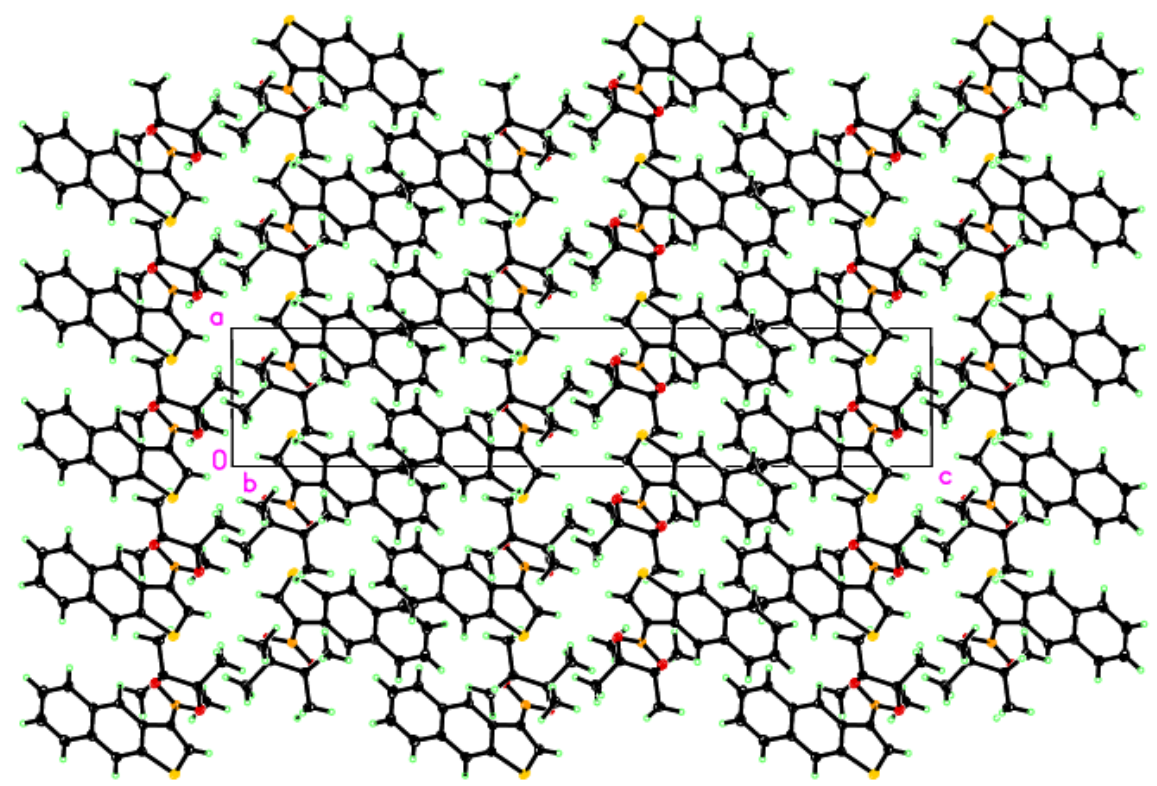

Packing diagram for compound 11a viewed down the $Y$-axis.

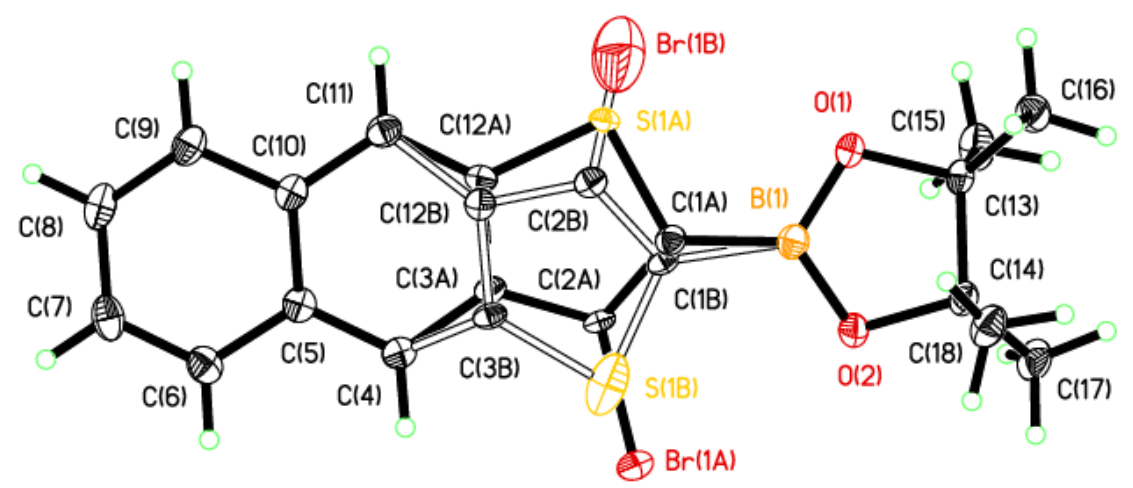

Structure of compound 11b showing both parts of the disordered model. Thermal ellipsoids have been drawn at the $50 \%$ probability level. The hydrogen atoms have not been labelled.

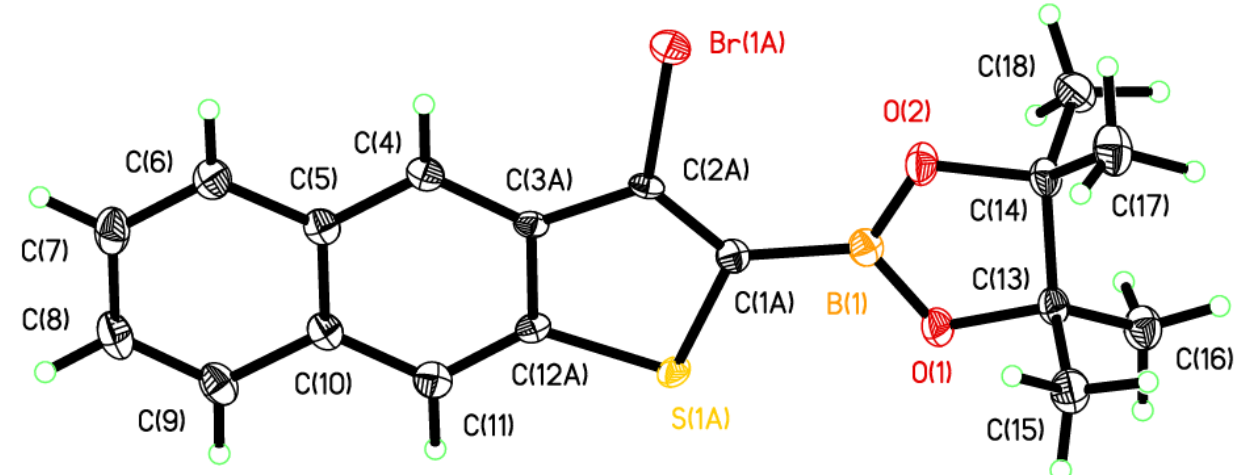


Structure of compound 11b showing only the main component of the disordered model. Thermal ellipsoids have been drawn at the $50 \%$ probability level. The hydrogen atoms have not been labelled.

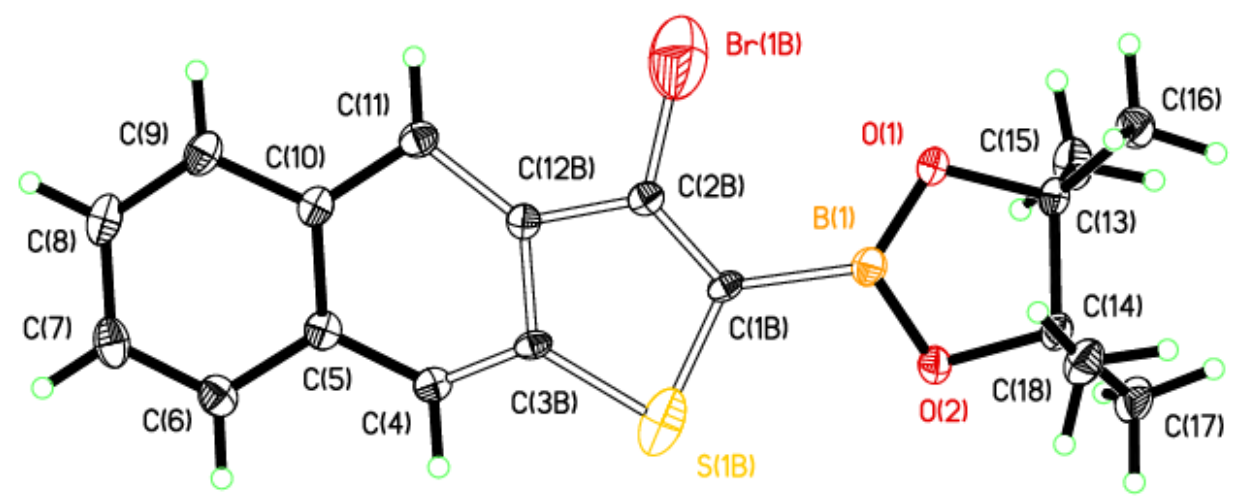

Structure of compound 13a showing only the minor component of the disordered model. Thermal ellipsoids have been drawn at the $50 \%$ probability level. The hydrogen atoms have not been labelled.

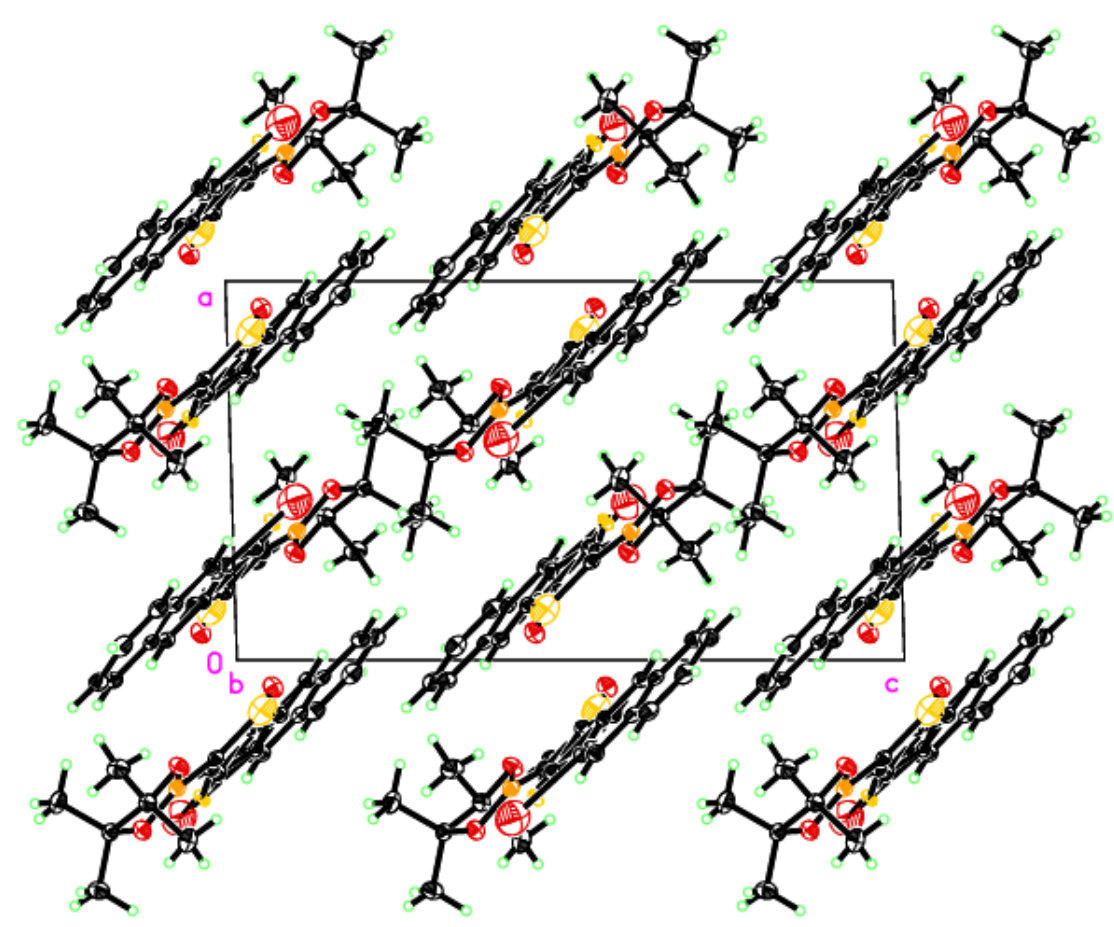

Packing diagram for compound 13a viewed down the $Y$-axis. 


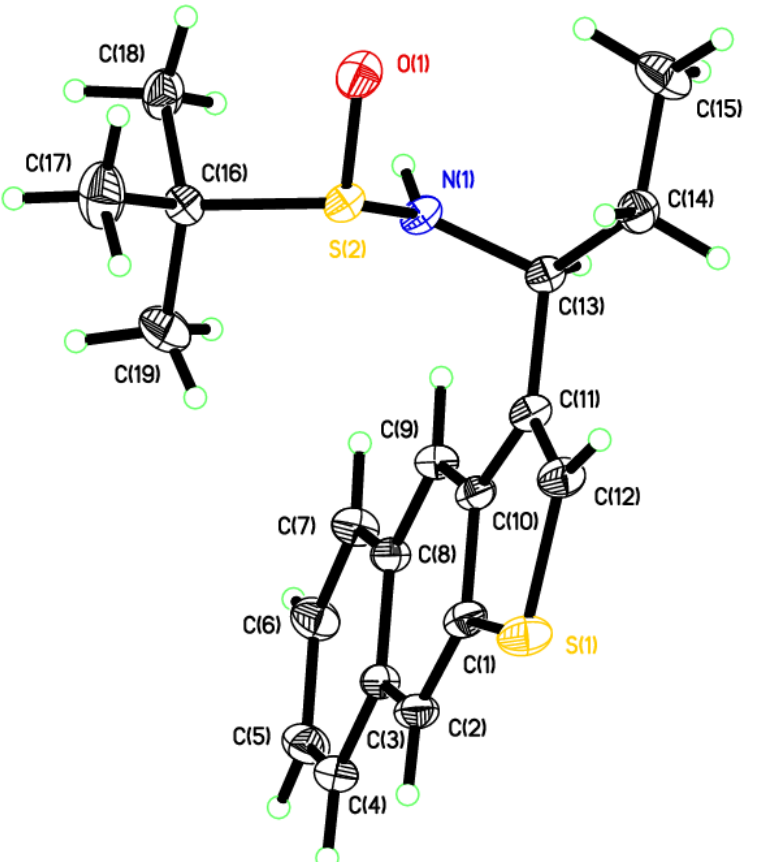

Structural diagram of compound compound 14a. Thermal ellipsoids have been drawn at the $50 \%$ probability level. Hydrogen atoms have not been labelled.

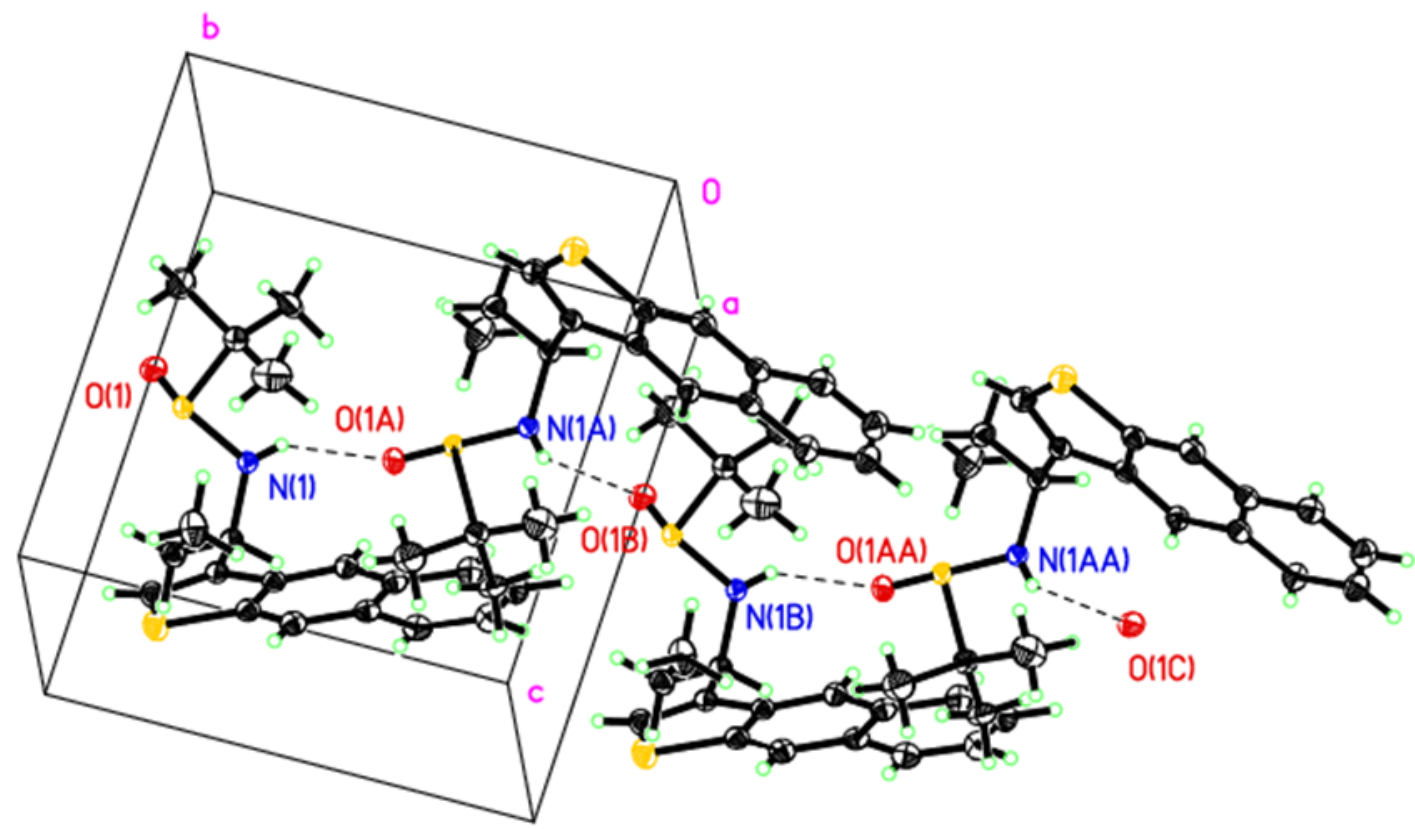

Structural diagram of the hydrogen bonded chain found in compound 14a. Thermal ellipsoids have been drawn at the $50 \%$ probability level. Hydrogen atoms have not been labelled. 


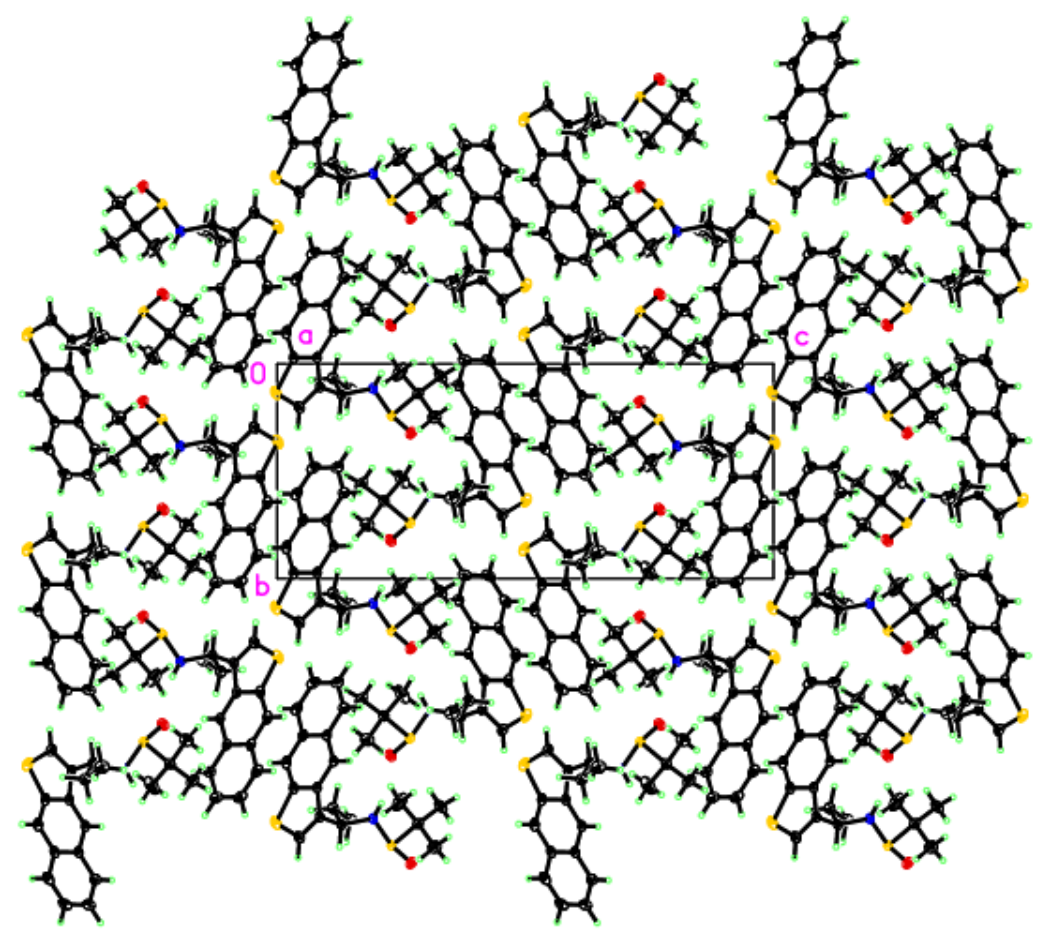

Packing diagram for compound 14a viewed down the $X$-axis.

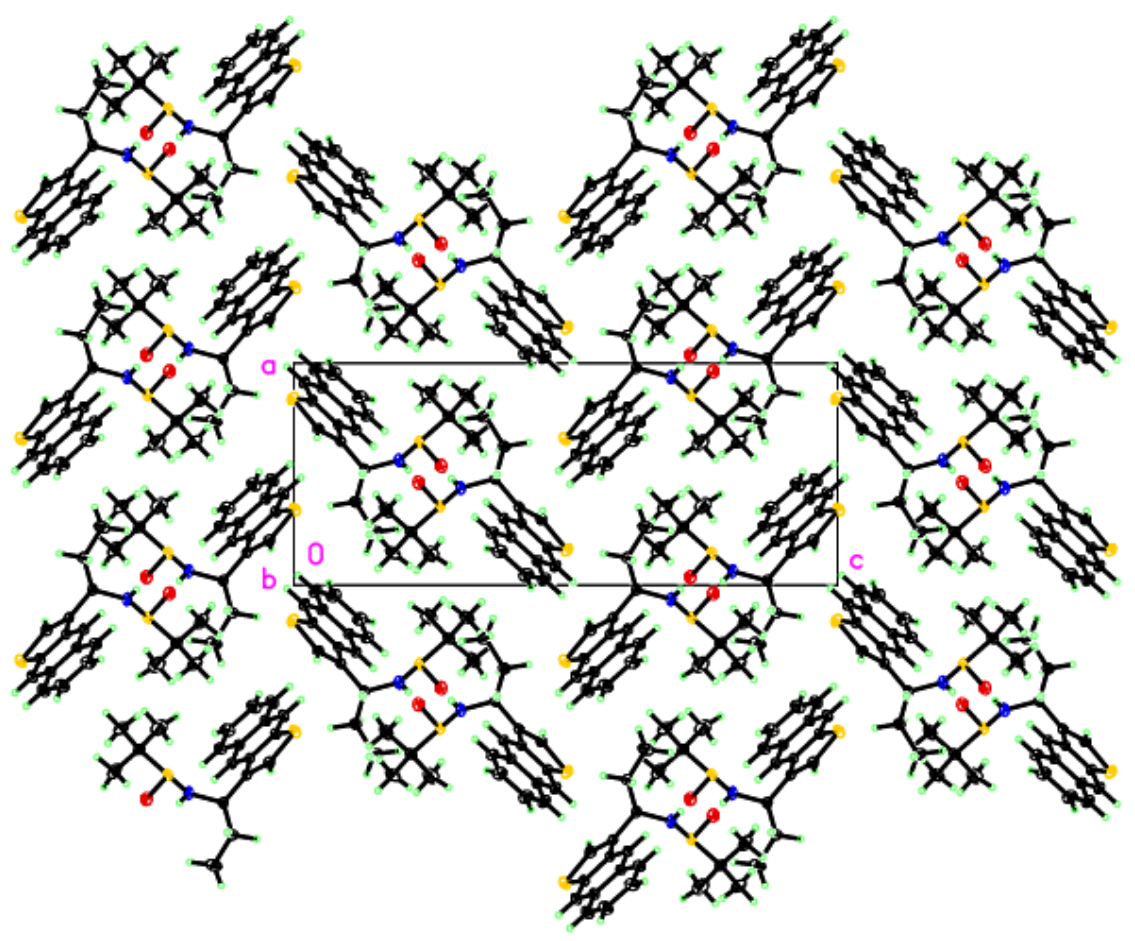

Packing diagram for compound 14a viewed down the $Y$-axis. 


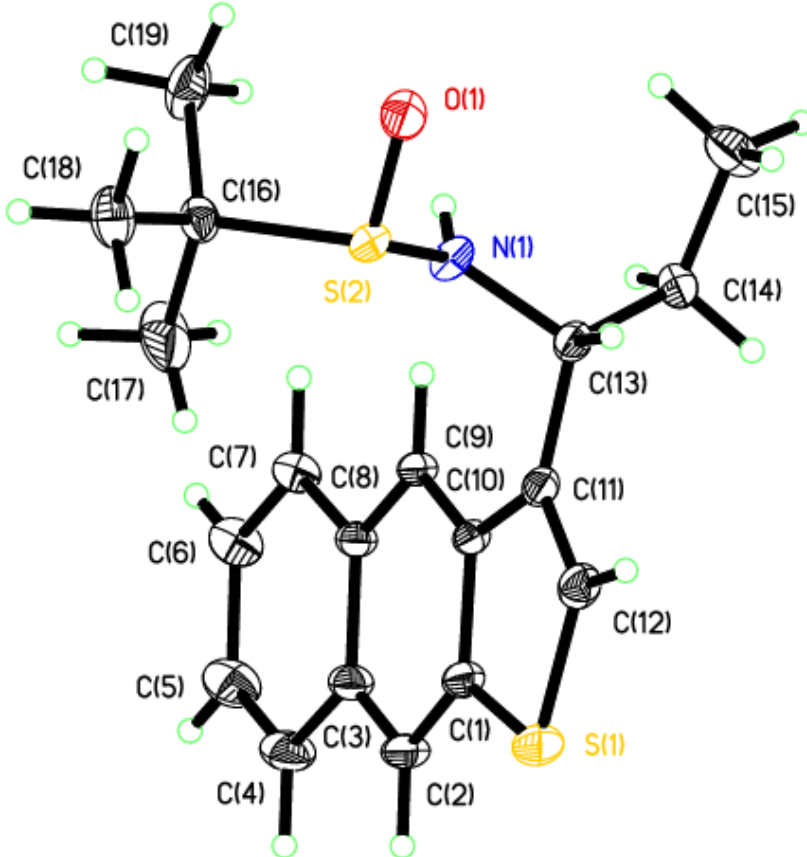

Structural diagram of compound compound 14b. Thermal ellipsoids have been drawn at the $50 \%$ probability level. Hydrogen atoms have not been labelled.

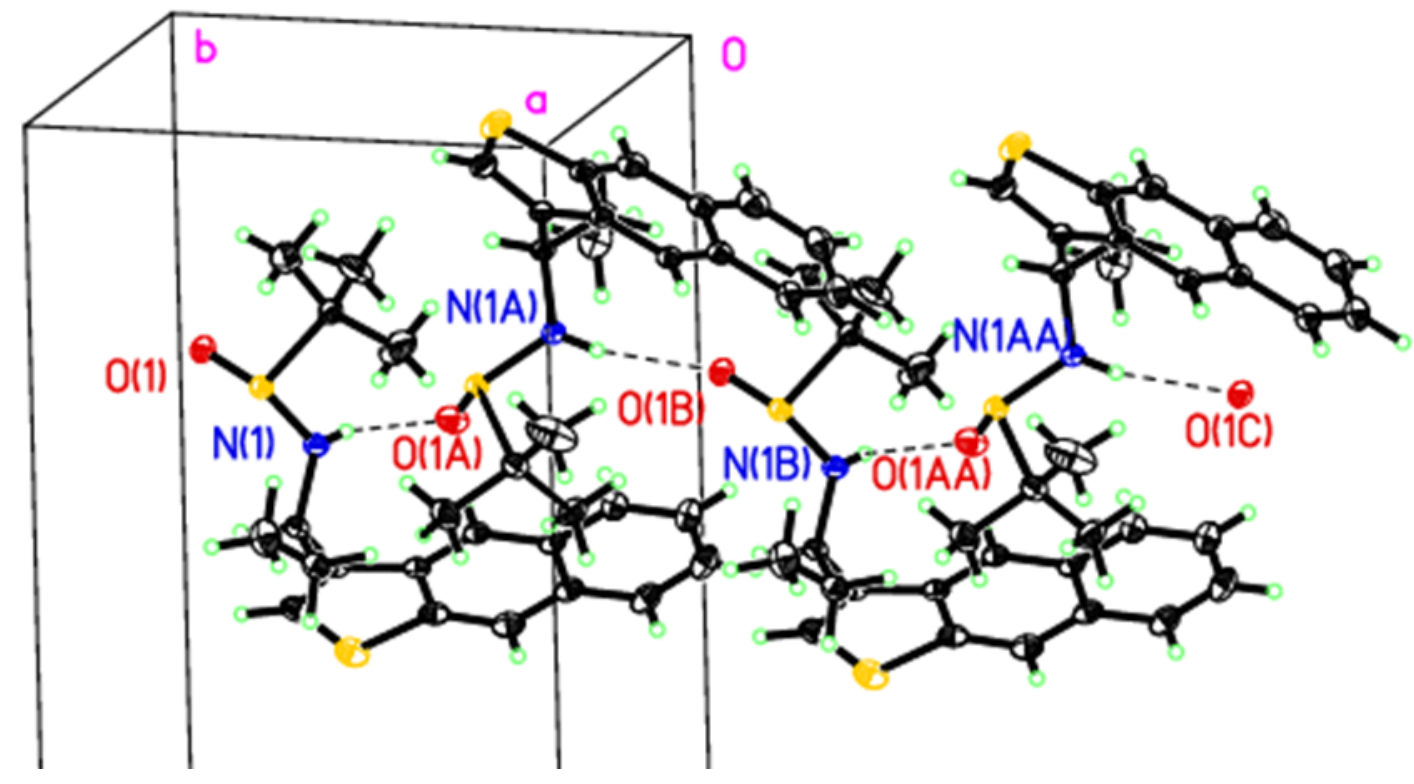

Structural diagram of the hydrogen bonded chains found in compound 14b. Thermal ellipsoids have been drawn at the $50 \%$ probability level. Hydrogen atoms have not been labelled. 


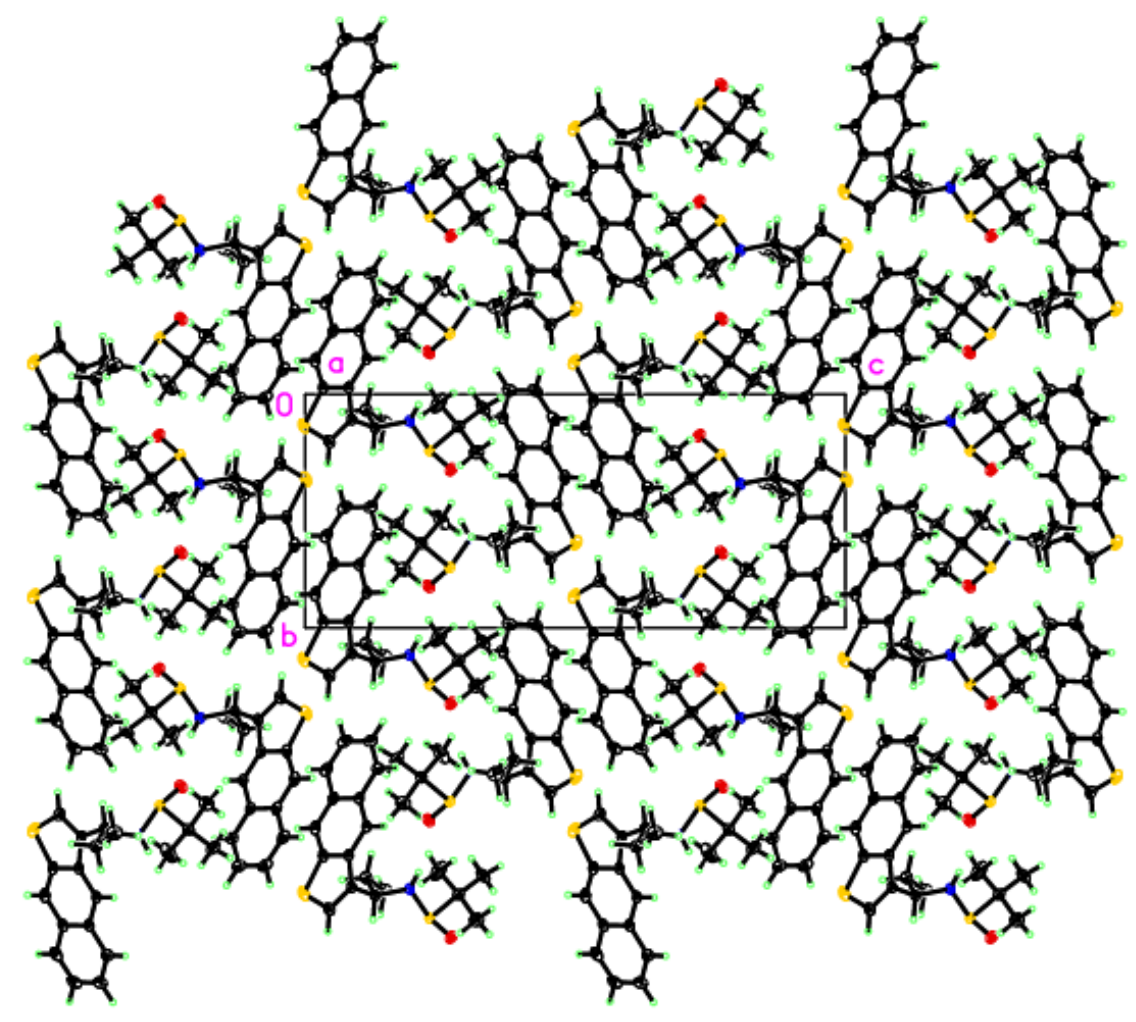

Packing diagram for compound 14b viewed down the $X$-axis.

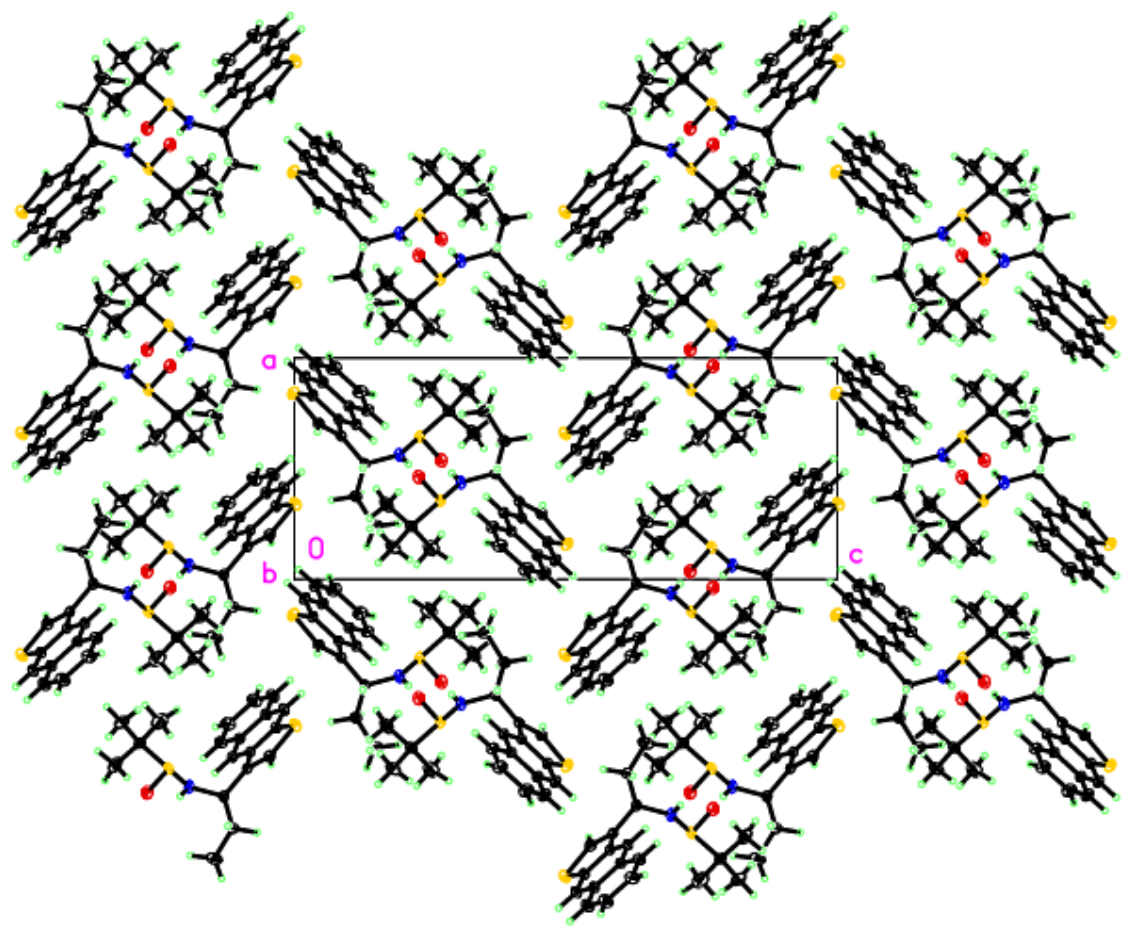

Packing diagram for compound $\mathbf{1 4 b}$ viewed down the $Y$-axis. 


\section{Experimental Procedures and Tabulated Data}

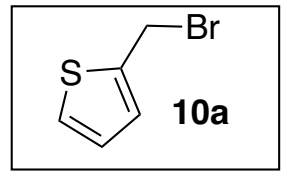

2-bromomethylthiophene (10a): The following reaction was not conducted under nitrogen to avoid contamination of the manifold with $\mathrm{HBr}$. Alcohol 9a $(1.66 \mathrm{~mL}, 17.5$ mmol, 1 equiv) was dissolved in $15 \mathrm{~mL}$ of diethyl ether, cooled to $0{ }^{\circ} \mathrm{C}$, and $\mathrm{PBr}_{3}(1.66$ $\mathrm{mL}, 17.5 \mathrm{mmol}, 1$ equiv) was added. The cooling bath was allowed to decay, and the reaction was stirred for 16 hours. The reaction was recooled and quenched by the dropwise addition of $30 \mathrm{~mL}$ of water. When $\mathrm{HBr}$ evolution ceased, the layers were separated, and the aqueous layer was extracted with a further $45 \mathrm{~mL}$ of ether. The combined organic layers were cautiously washed with saturated $\mathrm{NaHCO}_{3}$, then brine, then dried over $\mathrm{Na}_{2} \mathrm{SO}_{4}$. Concentration gave $10 \mathrm{a}$ as a yellow oil $(2.94 \mathrm{~g}, 16.6 \mathrm{mmol}, 95 \%$ yield), which was prone to decomposition as mentioned in the text and was used without further purification. ref

Lithium tetrachlorocuprate (0.5 M): Solid $\mathrm{LiCl}$ (1.26 g, $29.7 \mathrm{mmol}, 2$ equiv) and $\mathrm{CuCl}_{2}(2.00 \mathrm{~g}, 14.9 \mathrm{mmol}$, 1 equiv) were placed in a $50 \mathrm{~mL}$ Schlenk storage tube under nitrogen. THF $(30 \mathrm{~mL})$ was added, and the dark $\mathrm{red} / \mathrm{brown}$ reaction was stirred until all solids were dissolved. The dark red solution was stored under nitrogen at room temperature. A $0.1 \mathrm{M}$ solution of $\mathrm{Li}_{2} \mathrm{CuCl}_{4}$ in THF was also prepared in the same fashion.

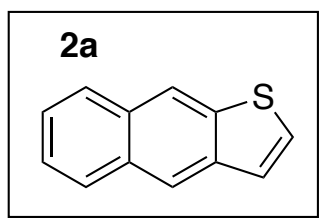

Naphthothiophene (2a): Magnesium turnings ( $0.315 \mathrm{~g}, 13.0 \mathrm{mmol}, 1.65$ equiv) were placed in a 3-neck flask equipped with a reflux condenser under nitrogen. Syringes with halide $7 \mathbf{b}(2.38 \mathrm{~mL}, 11.8 \mathrm{mmol}, 1.5$ equiv $)$ and THF $(15 \mathrm{~mL})$ were placed in the other septa. THF $(5 \mathrm{~mL})$ and halide $7 \mathbf{b}(0.3 \mathrm{~mL})$ were added, and the reaction was heated in an oil bath at $80^{\circ} \mathrm{C}$. A crystal of iodine, and $0.1 \mathrm{~mL}$ of dibromoethane were added. After several minutes, the color of the iodine disappeared, and THF and halide 10a were gradually added at a rate to maintain reflux. When the addition was complete, the light brown solution of Grignard reagent was stirred at reflux for a further hour, until only very small pieces of magnesium remained. It was then allowed to cool. Separately, lithium tetrachlorocuprate $(0.1 \mathrm{M}$ in THF, $7.85 \mathrm{~mL}, 0.785 \mathrm{mmol}, 0.1$ equiv) was added to a solution of bromide 10a $(1.39 \mathrm{~g}, 7.85 \mathrm{mmol}, 1$ equiv) in $8 \mathrm{~mL}$ THF. This bright orange mixture was cooled to $0 \mathrm{C}$. The Grignard solution $\mathbf{7 b}-\mathbf{M g}$ was transferred into this solution with a syringe and stainless steel needle. The red solution darkened during the addition, then suddenly turned very pale yellow. After completion of the addition, the solution remained yellow, but gradually became cloudy. The solution was stirred for 16 hours. The reaction was quenched with saturated $\mathrm{NH}_{4} \mathrm{Cl}$, and $10 \mathrm{~mL}$ aqueous ammonia was added. Diethyl ether $100 \mathrm{~mL}$ was added, and the mixture was vigorously shaken in a separatory funnel until it turned bright blue. The layers were separated, and the aqueous layer was extracted with another $100 \mathrm{~mL}$ of diethyl ether. The combined organic layers were washed with brine, and dried over $\mathrm{Na}_{2} \mathrm{SO}_{4}$, then concentrated. The resulting orange oil was used directly in the next step without further purification.

The orange oil was dissolved in $20 \mathrm{~mL}$ DCM and cooled to $0{ }^{\circ} \mathrm{C}$. Boron trifluoride etherate $(3.37 \mathrm{~mL}, 27.3$ mmol, 3.5 equiv) was added, and the reaction immediately turned deep black. The cooling bath was allowed to decay, and the reaction was stirred for 16 hours. The reaction was quenched by the addition of saturated $\mathrm{NaHCO}_{3}$. When bubbling ceased, layers were separated, and the aqueous layer was extracted with a further $50 \mathrm{~mL}$ DCM. The combined organic layers were dried over $\mathrm{Na}_{2} \mathrm{SO}_{4}$, and concentrated. The brown residue purified by flash chromatography on silica gel (1\% ethyl acetate/ hexanes). Combination of the product containing fractions yielded compound 2a as a white solid ( $0.936 \mathrm{~g}, 5.08 \mathrm{mmol}, 65 \%$ yield over 2 steps).

${ }^{1} \mathrm{H}$ NMR $\left(500 \mathrm{MHz}, \mathrm{CDCl}_{3}\right): \delta 8.38(\mathrm{~s}, 1 \mathrm{H}), 8.33(\mathrm{~s}, 1 \mathrm{H}), 7.99-7.97(\mathrm{~m}, 1 \mathrm{H}), 7.93-7.92(\mathrm{~m}, 1 \mathrm{H}), 7.52-7.47(\mathrm{~m}$, $3 \mathrm{H}$ ), 7.43 (ap. d, $J=5.64 \mathrm{~Hz}$ ).

${ }^{13} \mathrm{C}\left\{{ }^{1} \mathrm{H}\right\} \mathrm{NMR}\left(125 \mathrm{MHz}, \mathrm{CDCl}_{3}\right): \delta 139.0,138.4,131.1,131.0,128.4,128.3,127.4,125.4,125.1,123.6,122.0$, 120.8 . 


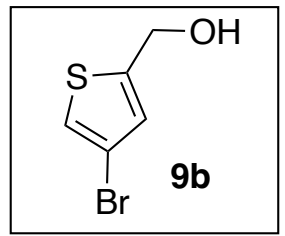

2-(4-bromothiophene)methanol (9b): The following reaction was conducted under air in an open flask. Commercially available 4-bromo-2-thiophenecarboxaldehyde 8 (10.0 g, 52 $\mathrm{mmol}, 1$ equiv) was dissolved in $100 \mathrm{~mL}$ ethanol and cooled to $0{ }^{\circ} \mathrm{C}$. Sodium borohydride ( $2.0 \mathrm{~g}, 53 \mathrm{mmol}, 1$ equiv) was cautiously added. The reaction was stirred for 2 hours, at which time an NMR aliquot showed complete consumption of the aldehyde. The reaction was cautiously quenched with $1.0 \mathrm{M}$ aqueous $\mathrm{HCl}$. When gas evolution ceased, volatiles were removed in vacuo. The residue was diluted with $100 \mathrm{~mL}$ water, and extracted with $100 \mathrm{~mL}$ diethyl ether, and a further $50 \mathrm{~mL}$ diethyl ether. The combined organic layers were dried with $\mathrm{Na}_{2} \mathrm{SO}_{4}$, and concentrated to yield alcohol $9 \mathrm{~b}$ (10.1 g, $52 \mathrm{mmol}$, quant) as a light brown liquid, which was used in the next step without further purification. Ref, NMR Data?

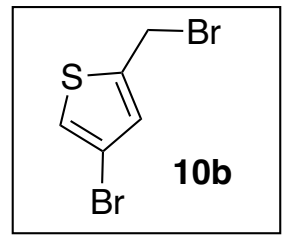

2-bromomethyl-4-bromothiophene (10b): The following reaction conducted under air, in a flask equipped with a septum, and 22 gauge needle for pressure release to avoid contamination of the manifold with $\mathrm{HBr}$. Alcohol $9 \mathrm{~b}$ (3.80 g, $19.6 \mathrm{mmol}, 1$ equiv) was dissolved in $20 \mathrm{~mL}$ of diethyl ether, cooled to $0{ }^{\circ} \mathrm{C}$, and $\mathrm{PBr}_{3}(2.00 \mathrm{~mL}, 21.6 \mathrm{mmol}, 1.1$ equiv) was added. The cooling bath was allowed to decay, and the reaction was stirred for 16 hours. The reaction was recooled and quenched by the dropwise addition of $30 \mathrm{~mL}$ of water. When $\mathrm{HBr}$ evolution ceased, the layers were separated, and the aqueous layer was extracted with a further $40 \mathrm{~mL}$ of ether. The combined organic layers were cautiously washed with saturated $\mathrm{NaHCO}_{3}$, then brine, then dried over $\mathrm{Na}_{2} \mathrm{SO}_{4}$. Concentration with a non-heated rotavap bath gave $\mathbf{1 0 b}$ as a yellow oil, which was dried under vacuum in a flask placed in an ice bath, which caused the compound solidify $(4.8 \mathrm{~g}, 18.8 \mathrm{mmol}, 95 \%$ yield). Decomposition was not observed with this compound in the solid state at this scale. An attempt to filter a highly concentrated ethereal solution of bromide 10b through basic alumina did result in darkening and exothermic decomposition, indicating this compound should be treated cautiously.

${ }^{1} \mathrm{H}$ NMR (500 MHz, $\left.\mathrm{CDCl}_{3}\right): \delta 7.21(\mathrm{~s}, 1 \mathrm{H}), 7.03(\mathrm{~s}, 1 \mathrm{H}), 4.65$ (s, 2H).

${ }^{13} \mathrm{C}\left\{{ }^{1} \mathrm{H}\right\}$ NMR $\left(125 \mathrm{MHz}, \mathrm{CDCl}_{3}\right): \delta 141.8,130.5,124.2,109.7,25.5$.

HRMS (APCI) $m / z[\mathrm{M}+\mathrm{H}]^{+}$calcd for $\mathrm{C}_{5} \mathrm{H}_{5} \mathrm{Br}^{79} \mathrm{Br}^{81} \mathrm{~S} 256.8453$ found 256.8455 .

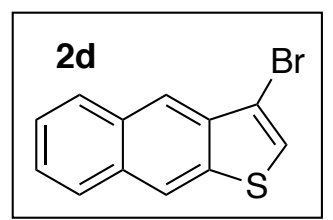

3-bromonaphthothiophene (2d): Magnesium turnings ( 0.729 g, $30.0 \mathrm{mmol}, 1.6$ equiv) were placed in a 3-neck flask equipped with a reflux condenser under nitrogen. Syringes with halide $7 \mathbf{b}(6.05 \mathrm{~mL}, 30.0 \mathrm{mmol}, 1.6$ equiv) and THF $(30 \mathrm{~mL})$ were placed in the other septa. THF $(5 \mathrm{~mL})$ and halide $7 \mathbf{b}(0.5 \mathrm{~mL})$ were added, and the reaction was heated in an oil bath at $70{ }^{\circ} \mathrm{C}$. A crystal of iodine, and $0.1 \mathrm{~mL}$ of dibromoethane were added. After several minutes, the color of the iodine disappeared, and THF and halide $\mathbf{7 b}$ were gradually added at a rate to maintain reflux. When the addition was complete, the light brown solution of Grignard reagent $\mathbf{7 b}$-Mg was stirred for a further hour, until only very small pieces of magnesium remained. It was then allowed to cool. Separately, lithium tetrachlorocuprate $(0.5 \mathrm{M}$ in THF, $6 \mathrm{~mL}, 3.0 \mathrm{mmol}$, 0.16 equiv) was added to a solution of bromide $10 \mathrm{~b}(4.8 \mathrm{~g}, 18.8 \mathrm{mmol}, 1$ equiv) in $15 \mathrm{~mL}$ THF. This bright orange mixture was cooled to $0{ }^{\circ} \mathrm{C}$. The Grignard solution $10 \mathrm{~b}$ was transferred into this solution with a syringe and stainless needle. The red solution darkened during the addition, then suddenly turned very pale yellow. After completion of the addition, the solution remained yellow, but gradually became cloudy. The solution was stirred for 16 hours. The reaction was quenched with saturated $\mathrm{NH}_{4} \mathrm{Cl}_{(\mathrm{aq})}$, and $10 \mathrm{~mL}$ aqueous ammonia was added. Diethyl ether 100 $\mathrm{mL}$ was added, and the mixture was vigorously shaken in a separatory funnel until it turned bright blue. The layers were separated, and the aqueous layer was extracted with another $100 \mathrm{~mL}$ of diethyl ether. The combined organic layers were washed with brine, and dried over $\mathrm{Na}_{2} \mathrm{SO}_{4}$, then concentrated. The resulting orange oil was used directly in the next step without further purification. 
The orange oil (18.8 mmol maximum theoretical amount) was dissolved in $60 \mathrm{~mL}$ DCM and cooled to $0{ }^{\circ} \mathrm{C}$. Boron trifluoride etherate $(3.70 \mathrm{~mL}, 30.1 \mathrm{mmol}, 1.6$ equiv) was added, and the reaction immediately turned deep black. The cooling bath was allowed to decay, and the reaction was stirred for 16 hours. The reaction was quenched by the addition of saturated $\mathrm{NaHCO}_{3}$. When bubbling ceased, layers were separated, and the aqueous layer was extracted with a further $50 \mathrm{~mL}$ DCM. The combined organic layers were dried over $\mathrm{Na}_{2} \mathrm{SO}_{4}$, and concentrated. The brown residue was redissolved in DCM, and several scoops of celite were added, and solvent was removed in vacuo. This was added on top of a pre-wetted silica-gel column, and elution was carried out with $1 \%$ ethyl acetate/ hexanes. Combination of the product containing fractions yielded compound $\mathbf{2 d}$ as a white solid ( $2.40 \mathrm{~g}, 9.12 \mathrm{mmol}, 48 \%$ yield over 2 steps). Spectral data were in accordance with literature values.

${ }^{1} \mathrm{H}$ NMR $\left(500 \mathrm{MHz}, \mathrm{CDCl}_{3}\right): \delta 8.33(\mathrm{~s}, 1 \mathrm{H}), 8.30(\mathrm{~s}, 1 \mathrm{H}), 8.05-8.03(\mathrm{~m}, 1 \mathrm{H}), 7.92-7.90(\mathrm{~m}, 1 \mathrm{H}), 7.53-7.50(\mathrm{~m}$, 2H), $7.52(\mathrm{~s}, 1 \mathrm{H})$.

${ }^{13} \mathrm{C}\left\{{ }^{1} \mathrm{H}\right\} \mathrm{NMR}\left(125 \mathrm{MHz}, \mathrm{CDCl}_{3}\right): \delta 136.5,136.2,131.5,131.2,128.6,127.3,126.1,125.6,125.3,121.9,121.3$, 107.4.

HRMS (APCI) $m / z[\mathrm{M}+\mathrm{H}]^{+}$calcd for $\mathrm{C}_{12} \mathrm{H}_{8} \mathrm{Br}^{79} \mathrm{~S} 262.9525$ found 262.9516 .

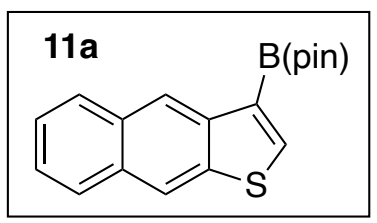

3-(4,4,5,5-tetramethyl-1,3,2-dioxaborolan2-yl)-naphthothiophene (11a): In a recovery flask, 3-bromonaphthothiophene $\mathbf{2 d}(500 \mathrm{mg}, 1.9 \mathrm{mmol}, 1$ equiv) was dissolved in $3 \mathrm{~mL}$ THF. Separately $6 \mathrm{~mL}$ of THF was placed in a Schlenk flask and cooled to $-84^{\circ} \mathrm{C}$ (liquid nitrogen/ethyl acetate). N-butyllithium $(2.5 \mathrm{M}$ in hexanes, $0.87 \mathrm{~mL}, 2.2 \mathrm{mmol}, 1.1$ equiv) was added to the Schlenk flask, and the solution was allowed to stir at $-84^{\circ} \mathrm{C}$ for another 10 minutes. The solution of 3-naphthothiophene was added over 1 minute, running the solution down the inside of the flask to facilitate pre-cooling. The solution became inky blue in colour, and occasionally a greyish precipitate formed. The reaction was stirred at $-84{ }^{\circ} \mathrm{C}$ for 5 minutes, then $i \operatorname{PrOB}(\operatorname{pin})(0.47 \mathrm{~mL}, 2.3 \mathrm{mmol}, 1.2$ equiv) was added. The dark greenish reaction was stirred for 10 minutes, warmed to $0{ }^{\circ} \mathrm{C}$ for 5 minutes, then quenched with $10 \mathrm{~mL}$ of $2 \mathrm{M} \mathrm{HCl}$. To the solution was added $25 \mathrm{~mL}$ of dichloromethane, and the mixture was vigorously stirred for 5 minutes. The layers were separated. The aqueous layer washed with an additional $25 \mathrm{~mL}$ dichloromethane, and the combined residues were dried over $\mathrm{Na}_{2} \mathrm{SO}_{4}$ and concentrated. The brown residue was purified by flash chromatography ( $1 \%$ ethyl acetate/hexanes) to afford boronic ester 11a as a white solid (338 $\mathrm{mg}, 1.09 \mathrm{mmol}, 57 \%$ yield). S

${ }^{1} \mathrm{H}$ NMR (500 MHz, $\left.\mathrm{CDCl}_{3}\right): \delta 8.87$ (s, 1H), 8.39 (s, 1H), $8.18(\mathrm{~s}, 1 \mathrm{H}), 8.09-8.07(\mathrm{~m}, 1 \mathrm{H}), 7.92-7.90(\mathrm{~m}, 1 \mathrm{H})$, $7.50-7.46(\mathrm{~m}, 2 \mathrm{H}), 1.44(\mathrm{~s}, 12 \mathrm{H})$.

${ }^{13} \mathrm{C}\left\{{ }^{1} \mathrm{H}\right\}$ NMR $\left(125 \mathrm{MHz}, \mathrm{CDCl}_{3}\right): \delta 141.8,141.5,139.6,131.2,130.9,128.9,127.3,125.3,124.8,123.9,120.4$, 83.9, 25.1 .

${ }^{11} \mathrm{~B}$ NMR (160 MHz, $\left.\mathrm{CDCl}_{3}\right): \delta 29.1$ (br. s).

HRMS (ESI) $m / z[\mathrm{M}+\mathrm{Na}]^{+}$calcd for $\mathrm{C}_{18} \mathrm{H}_{19} \mathrm{BNaO}_{2} 333.1091$ found 333.1082.

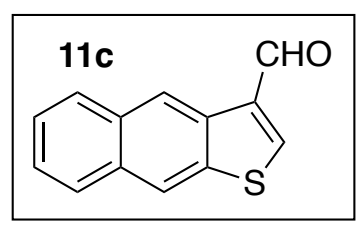

3-naphthothiophenecarboxaldehyde (11c): In a recovery flask, 3bromonaphthothiophene $\mathbf{2 d}(1.60 \mathrm{~g}, 6.08 \mathrm{mmol}, 1$ equiv) was dissolved in $4 \mathrm{~mL}$ THF. Separately $6 \mathrm{~mL}$ of THF was placed in a Schlenk flask and cooled to $-84{ }^{\circ} \mathrm{C}$ (liquid nitrogen/ethyl acetate). N-butyllithium $2.5 \mathrm{M}$ in hexanes $(3.89 \mathrm{~mL}, 9.72 \mathrm{mmol}, 1.6$ equiv) was added to the Schlenk, and the solution was allowed to stir at $-84{ }^{\circ} \mathrm{C}$ for another 10 minutes. The solution of 3-bromonaphthothiophene $\mathbf{2 d}$ was added over 1 minute, running the solution down the inside of the flask to facilitate pre-cooling, with a further $2 \mathrm{~mL}$ THF used to quantitiate the transfer. The solution became inky blue in colour, and occasionally a greyish precipitate formed. The reaction was stirred at $-84^{\circ} \mathrm{C}$ for 10 minutes, then DMF $(0.94 \mathrm{~mL}, 12 \mathrm{mmol}, 2$ equiv) was added. The dark greenish reaction was stirred for 10 minutes, warmed to $0{ }^{\circ} \mathrm{C}$ for 5 minutes, then quenched with $10 \mathrm{~mL} \mathrm{NH}_{4} \mathrm{Cl}_{(\mathrm{aq})}$ and $10 \mathrm{~mL} 2 \mathrm{M} \mathrm{HCl}$. To the solution was added $25 \mathrm{~mL}$ of dichloromethane, and the mixture was vigorously 
stirred for 5 minutes. The layers were separated. The aqueous layer washed with an additional $25 \mathrm{~mL}$ dichloromethane, and the combined residues were dried over $\mathrm{Na}_{2} \mathrm{SO}_{4}$ and concentrated. The brown residue was purified by flash chromatography (5\%-10\% ethyl acetate/hexanes) to afford aldehyde 11c as an orange/yellow solid (749 mg, $3.52 \mathrm{mmol}, 58 \%$ yield). Minor, inseparable impurities were noted in the NMR spectra.

${ }^{1} \mathrm{H}$ NMR (500 MHz, $\left.\mathrm{CDCl}_{3}\right): 10.15(\mathrm{~s}, 1 \mathrm{H}), 9.21(\mathrm{~s}, 1 \mathrm{H}), 8.36(\mathrm{~s}, 1 \mathrm{H}), 8.32(\mathrm{~s}, 1 \mathrm{H}), 8.08-8.03(\mathrm{~m}, 1 \mathrm{H}), 7.92-$ $7.88(\mathrm{~m}, 1 \mathrm{H}), 7.57-7.50(\mathrm{~m}, 2 \mathrm{H})$.

${ }^{13} \mathrm{C}\left\{{ }^{1} \mathrm{H}\right\}$ NMR $\left(125 \mathrm{MHz}, \mathrm{CDCl}_{3}\right): 185.1,146.3,138.2,136.1,133.2,131.7,131.6,128.9,127.2,126.3,125.7$, $123.9,120.8$.

HRMS (ESI) $m / z$ [M $+\mathrm{Na}]^{+}$calcd for $\mathrm{C}_{13} \mathrm{H}_{8} \mathrm{NaOS} 235.0188$ found 235.0197.

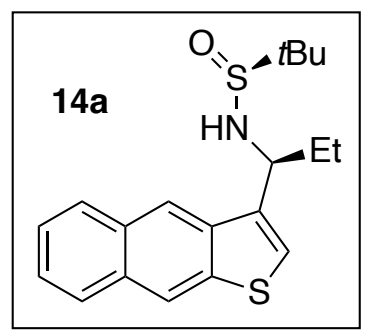

Sulfinamides (14a and b): In a recovery flask, 3-bromonaphthothiophene $\mathbf{2 d}$ (1.00 $\mathrm{g}, 3.80 \mathrm{mmol}, 1$ equiv) was dissolved in $5 \mathrm{~mL}$ THF. Separately $7 \mathrm{~mL}$ of THF was placed in a Schlenk flask and cooled to $-84{ }^{\circ} \mathrm{C}$ (liquid nitrogen/ethyl acetate). Nbutyllithium $2.5 \mathrm{M}$ in hexanes $(1.98 \mathrm{~mL}, 4.94 \mathrm{mmol}, 1.3$ equiv) was added to the Schlenk, and the solution was allowed to stir at $-84^{\circ} \mathrm{C}$ for another 10 minutes. The solution of 3-bromonaphthothiophene $\mathbf{2 d}$ was added over 1 minute, running the solution down the inside of the flask to facilitate pre-cooling, with a further $2 \mathrm{~mL}$ THF used to quantitiate the transfer. The solution became inky blue in colour. The reaction was stirred at $-84^{\circ} \mathrm{C}$ for 5 minutes, then a solution of imine $13(0.88 \mathrm{~g}$, xx mmol, $x x$ equiv) in $3 \mathrm{~mL}$ THF was added. The resulting clear orange reaction mixture was stirred for 2 hours, then allowed to warm to room temperature. The mixture was then quenched with $10 \mathrm{~mL} \mathrm{NH}_{4} \mathrm{Cl}_{(\mathrm{aq})}$. The reaction was extracted with diethyl ether. The combined organic layers were dried over $\mathrm{Na}_{2} \mathrm{SO}_{4}$, and concentrated. The resulting residue was purified by flash chromatography (40\% ethyl acetate/hexanes moving to $50 \%$ when the first diastereomer eluted). The less polar diastereomer 14a was the major one. Compound 14a was obtained as a yellow tacky solid $(631 \mathrm{mg}, \mathrm{xx} \mathrm{mmol}, \mathrm{xx} \%$ yield). Minor diastereomer $14 \mathbf{b}$ was obtained as a colourless tacky solid (263 mg, xx mmol, xx\% yield). X-Ray quality crystals of both diastereomers were obtained by slow evaporation of diethyl ether solutions of the products.

${ }^{1}$ H NMR (500 MHz, CDCl $)$ ): $\delta 8.43(\mathrm{~s}, 1 \mathrm{H}), 8.35(\mathrm{~s}, 1 \mathrm{H}), 8.00-7.88(\mathrm{~m}, 2 \mathrm{H}), 7.49-7.46(\mathrm{~m}, 3 \mathrm{H}), 4.89-4.86$ (m, 1H), 2.22-2.17 (m, 2H), 1.24 (s, 9H), 0.94 (ap. t, $J=7.4 \mathrm{~Hz}, 3 \mathrm{H})$.

${ }^{13}$ C NMR (125 MHz, $\left.\mathbf{C D C l}_{3}\right): \delta$ 139.2, 136.7, 136.0, 131.1, 130.7, 128.7, 127.2, 125.8, 125.7, 125.2, 121.3, $120.9,55.9,55.0,27.9,27.7,10.4$.

HRMS (ESI) $m / z[\mathrm{M}+\mathrm{Na}]^{+}$calcd for $\mathrm{C}_{32} \mathrm{H}_{28} \mathrm{~N}_{2} \mathrm{NaS}_{2} 527.1586$ found 527.1586

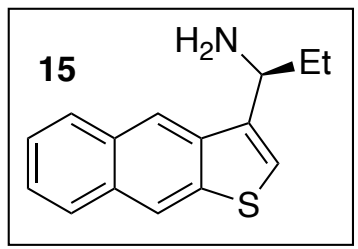

Chiral Amine 15a: In a $30 \mathrm{~mL}$ round-bottom flask, compound 14a (500 mg, xx mmol, 1 equiv) was dissolved in $10 \mathrm{~mL}$ of a $1: 1$ mixture of diethyl ether and dichloromethane. To the mixture was added $2 \mathrm{M} \mathrm{HCl}$ in diethyl ether $(2.89 \mathrm{~mL}, 5.79$ mmol, 4 equiv). The resulting tan suspension was stirred for 12 hours. The product was collected by filtration, and washed with additional diethyl ether. The $\mathrm{HCl}$ salt was collected as a beige solid (362 $\mathrm{mg}$, $\mathrm{xx} \mathrm{mmol}, \mathrm{xx} \%$ yield). Due to low solubility, the $\mathrm{HCl}$ salt was characterized as the free-base. A portion was suspended in dichloromethane, and washed with $1 \mathrm{M} \mathrm{NaOH}_{(\mathrm{aq})}$. The organic layer was dried over $\mathrm{Na}_{2} \mathrm{SO}_{4}$, and concentrated to give the freebase as a beige oil.

${ }^{1}$ H NMR (500 MHz, CDCl 3 ): $\delta 8.35$ (ap. d, $\left.J=7.2 \mathrm{~Hz}, 2 \mathrm{H}\right), 8.00-7.89$ (m, 2H), 7.49-7.45 (m, 2H), 7.38 (s, $1 \mathrm{H}), 4.43-4.41(\mathrm{~m}, 1 \mathrm{H}), 2.10-2.02(\mathrm{~m}, 1 \mathrm{H}), 1.91-1.82(\mathrm{~m}, 1 \mathrm{H}), 1.03$ (ap. t, $J=7.4 \mathrm{~Hz}, 3 \mathrm{H})$. 
${ }^{13}$ C NMR (125 MHz, $\left.\mathbf{C D C l}_{3}\right): \delta 139.6,137.5,131.1,130.7,128.6,127.3,125.5,125.1,122.9,121.2,120.4$, 52.3, 30.8, 11.0.

HRMS (ESI) $m / z[\mathrm{M}+\mathrm{Na}]^{+}$calcd for $\mathrm{C}_{15} \mathrm{H}_{15} \mathrm{NNaS} 264.081741$ found 264.0822 
NMR Data:
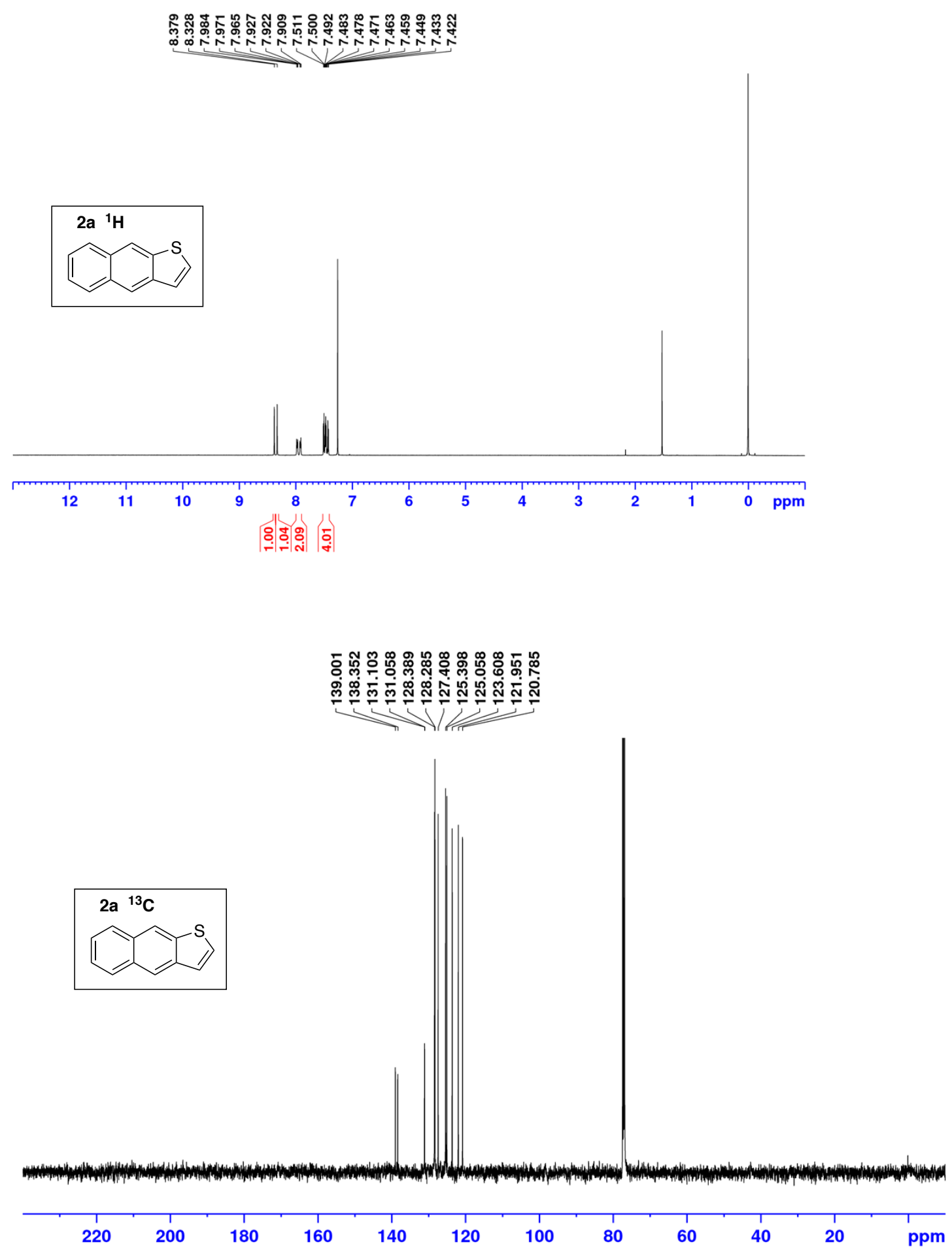


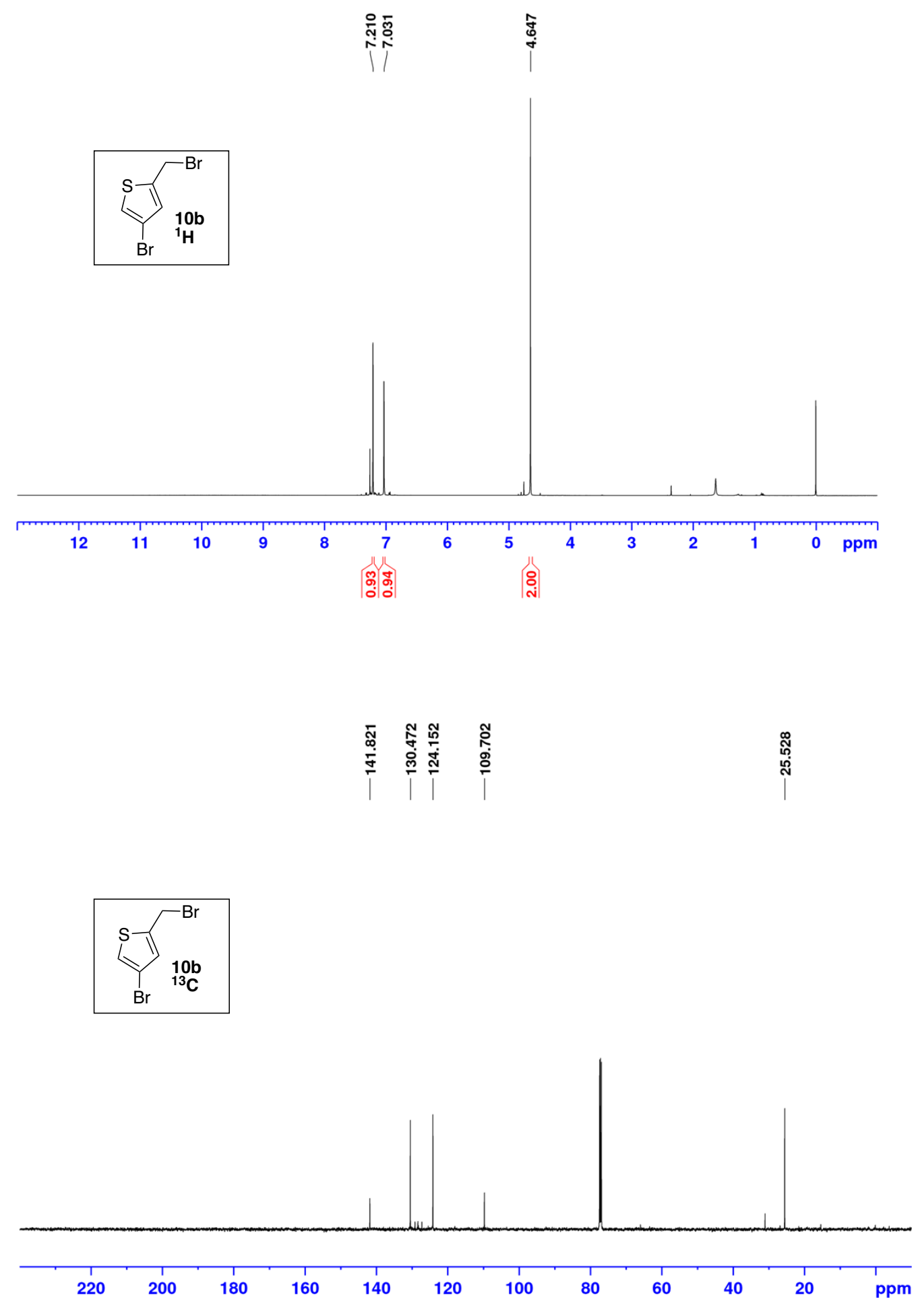




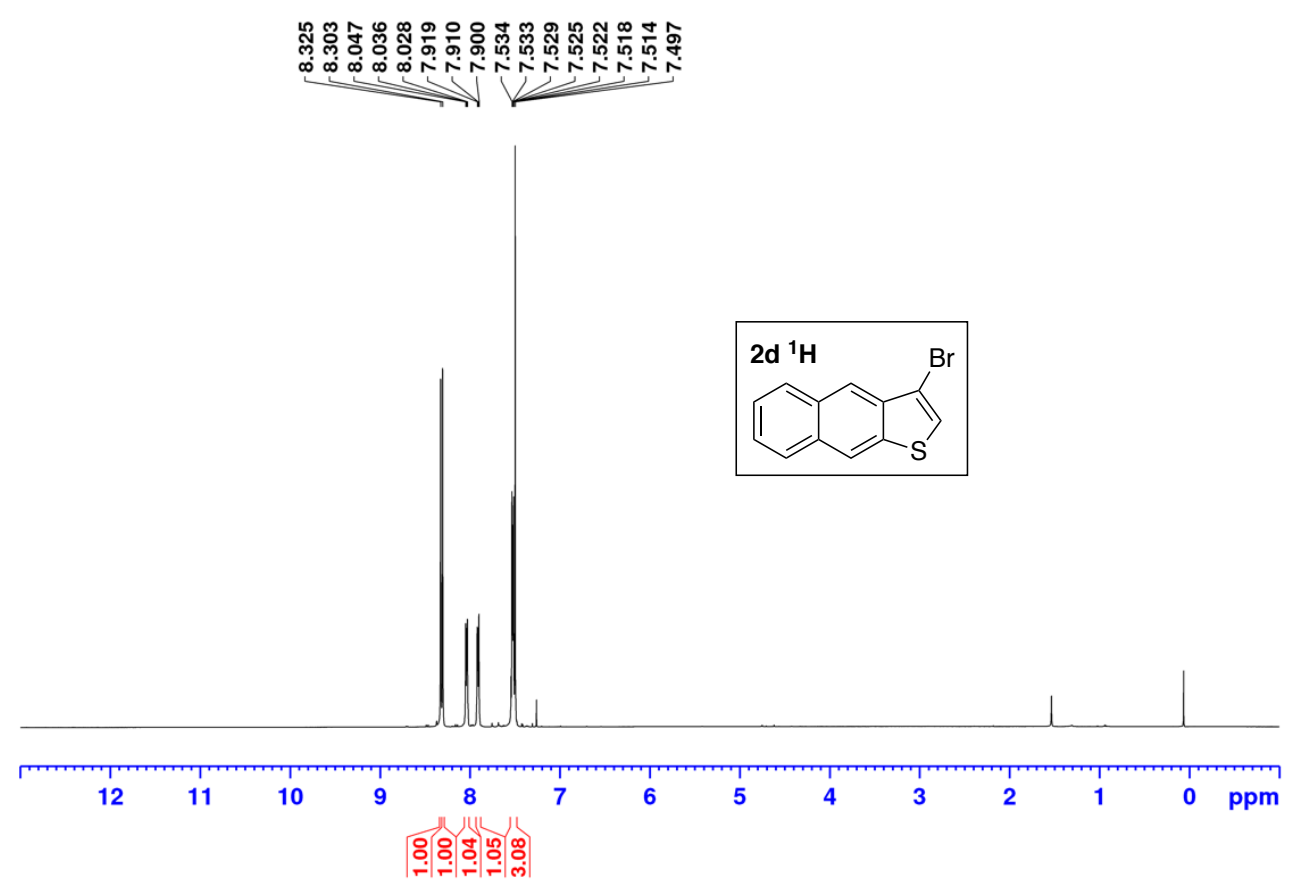

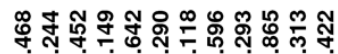

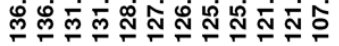
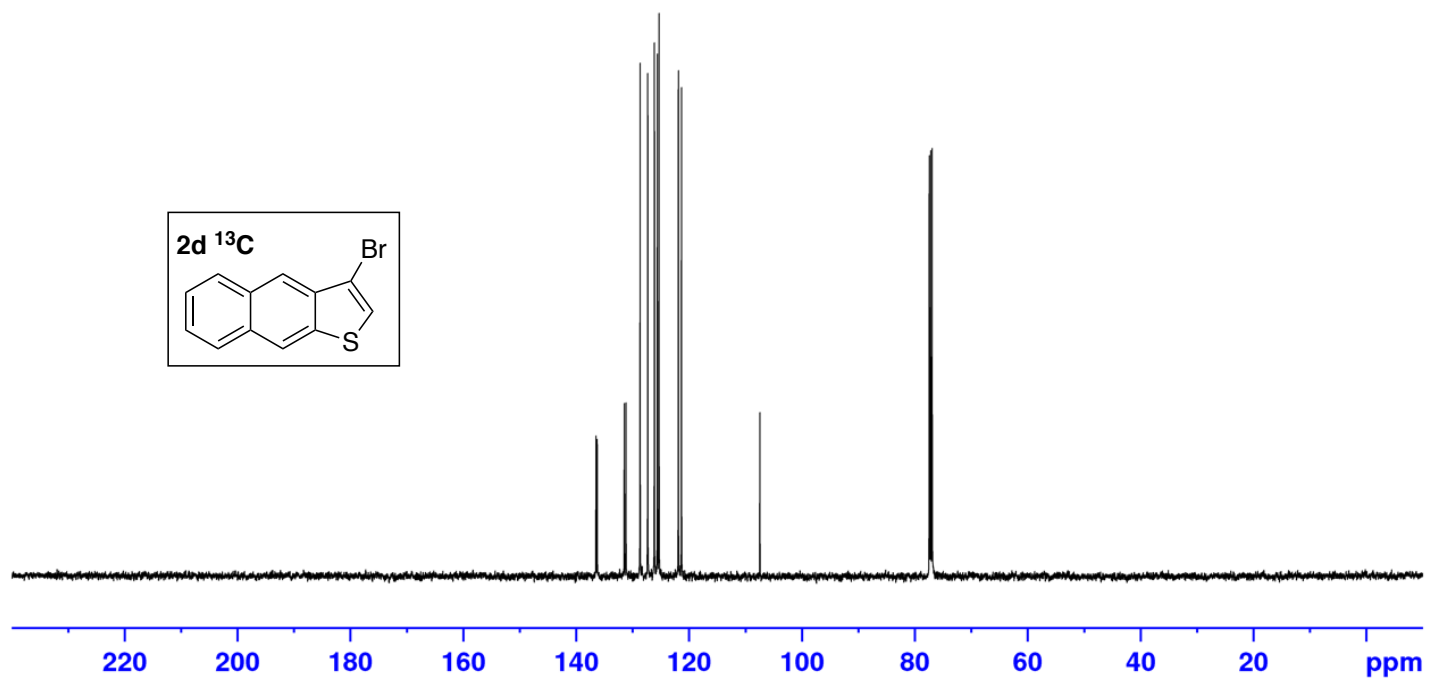

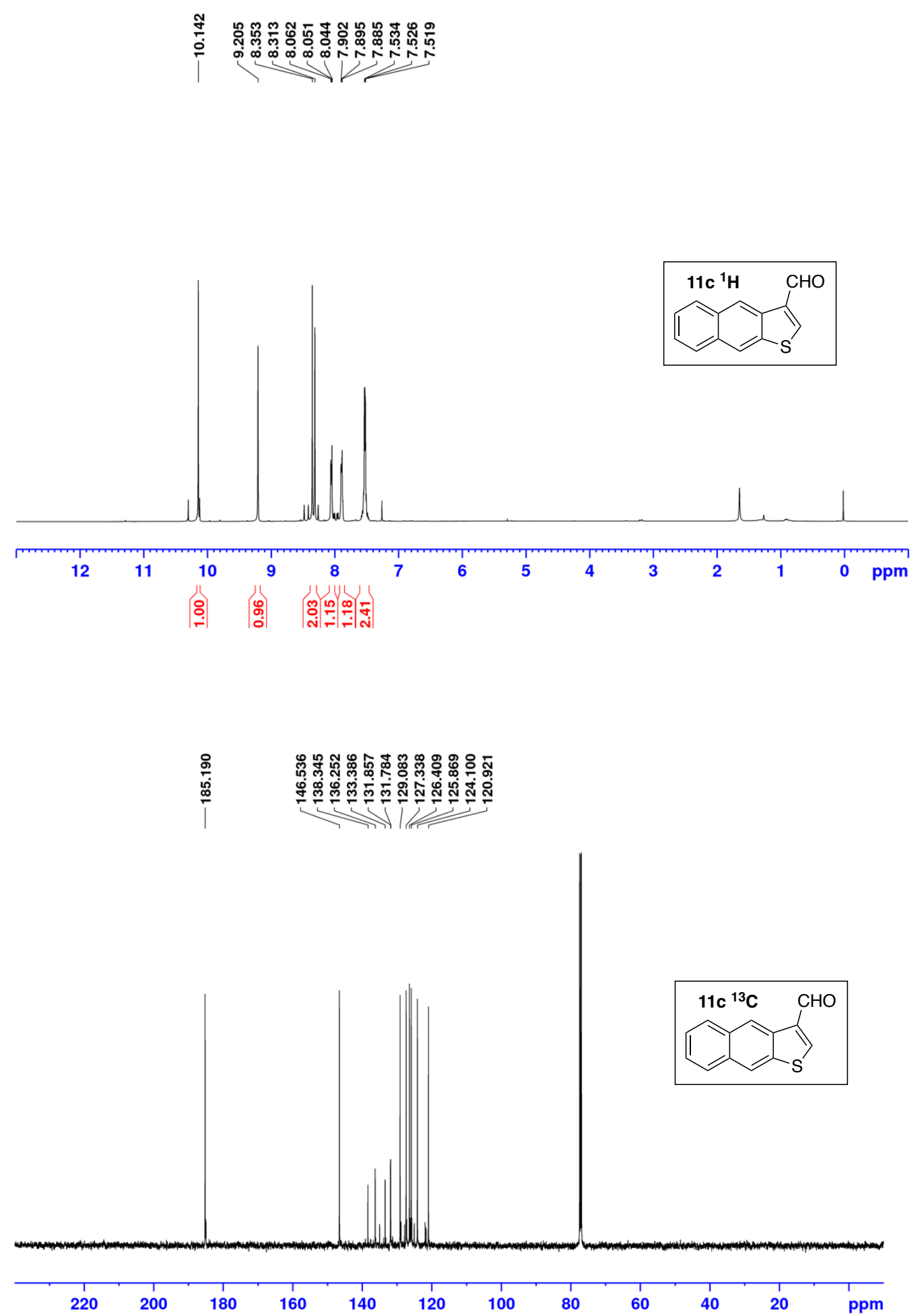
11a ${ }^{1} \mathrm{H} \quad \mathrm{B}$ (pin)
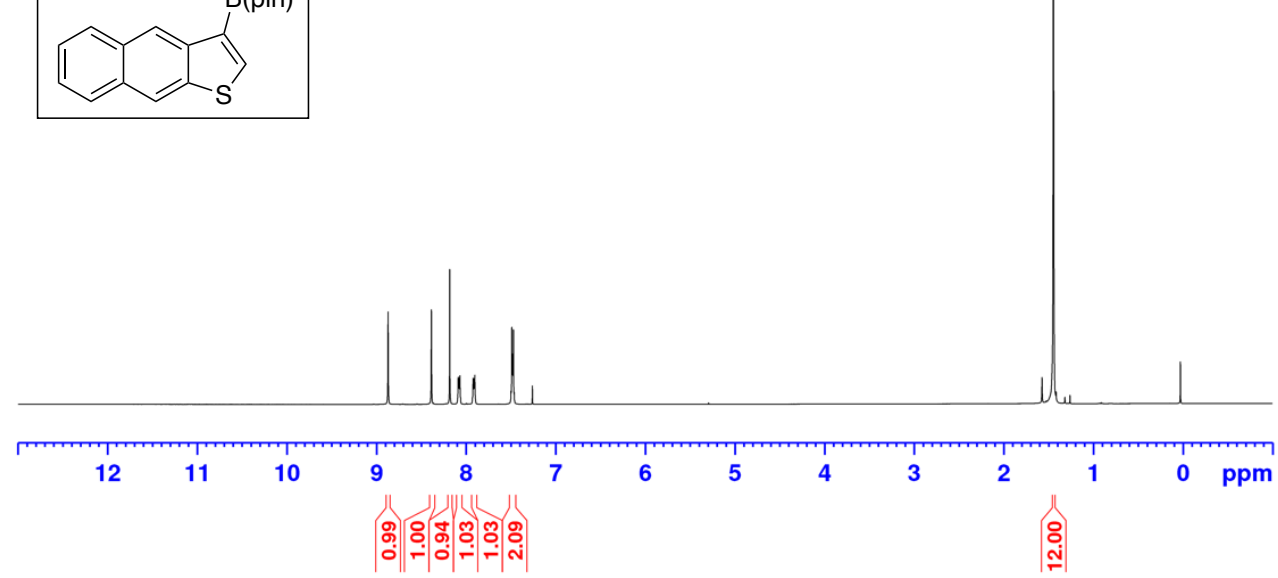

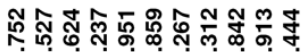

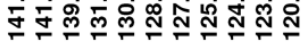
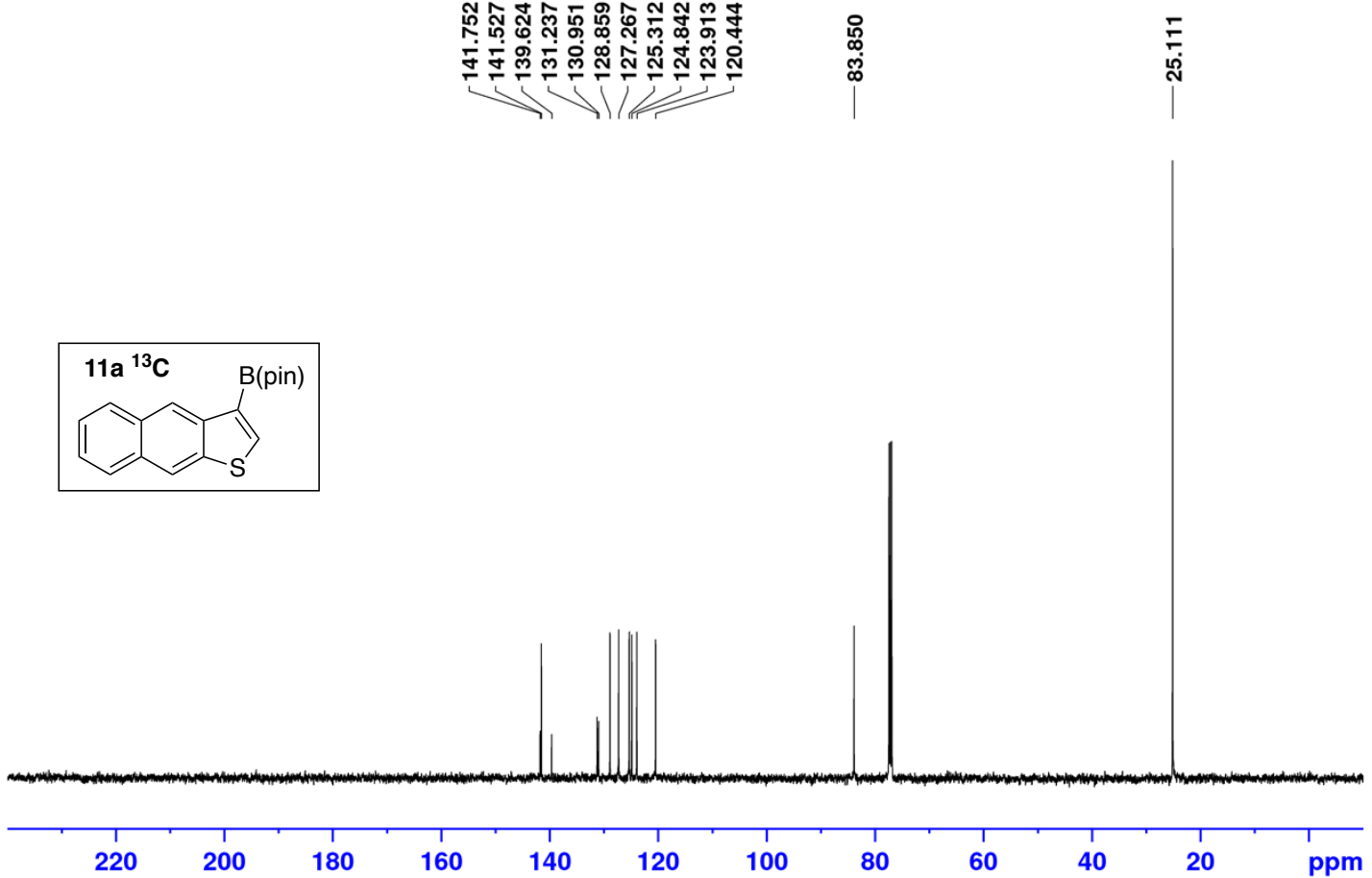


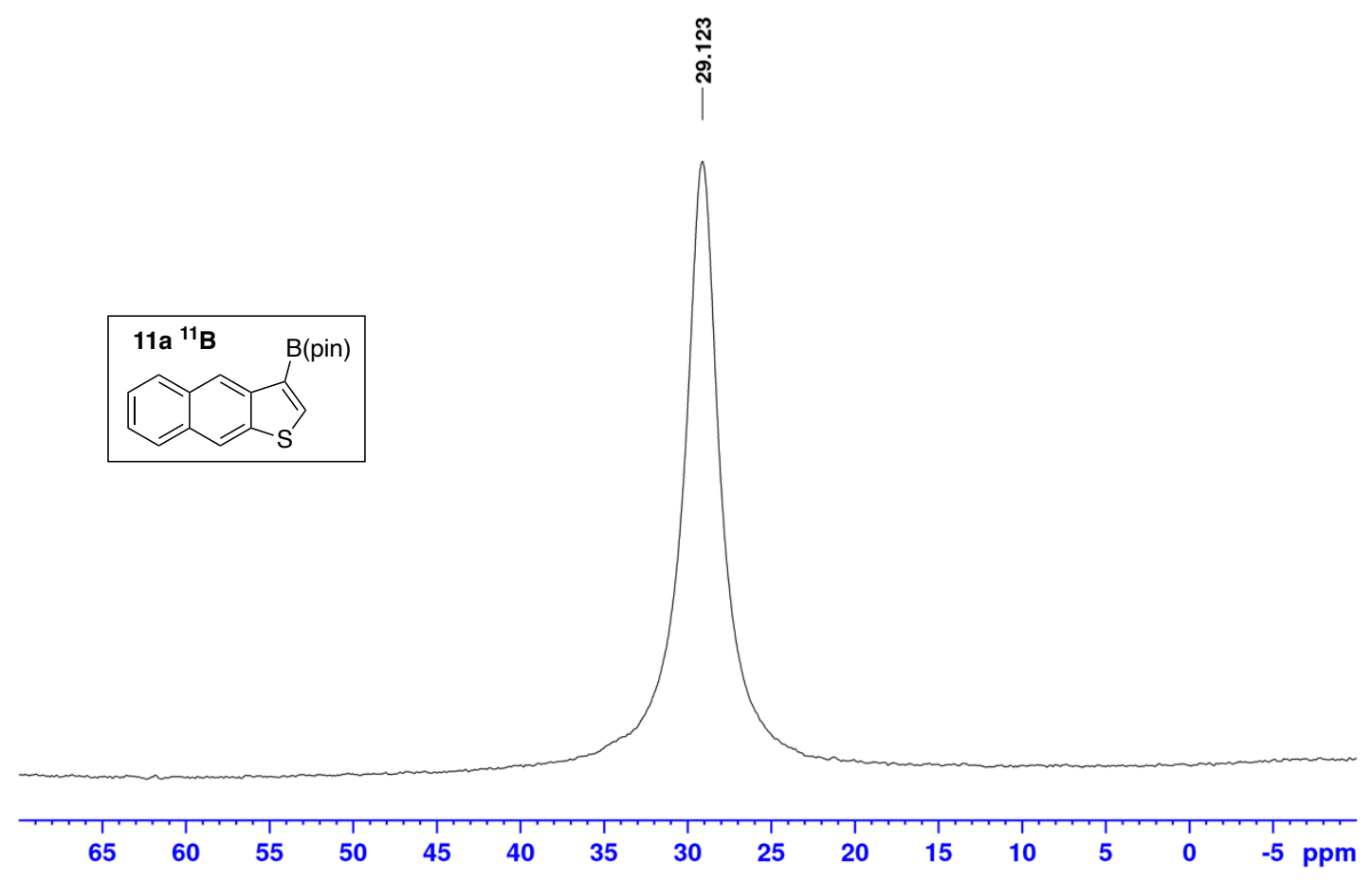



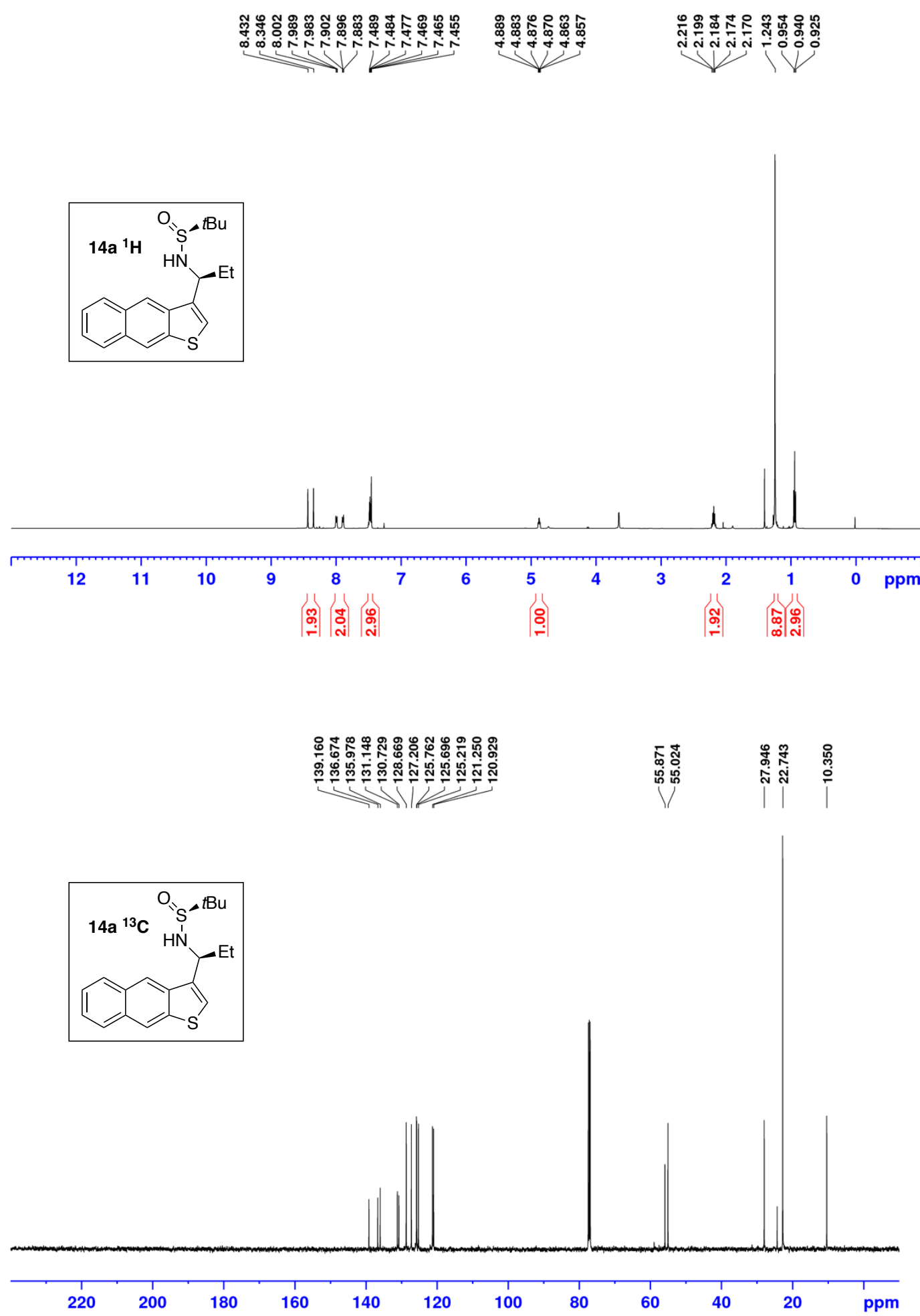

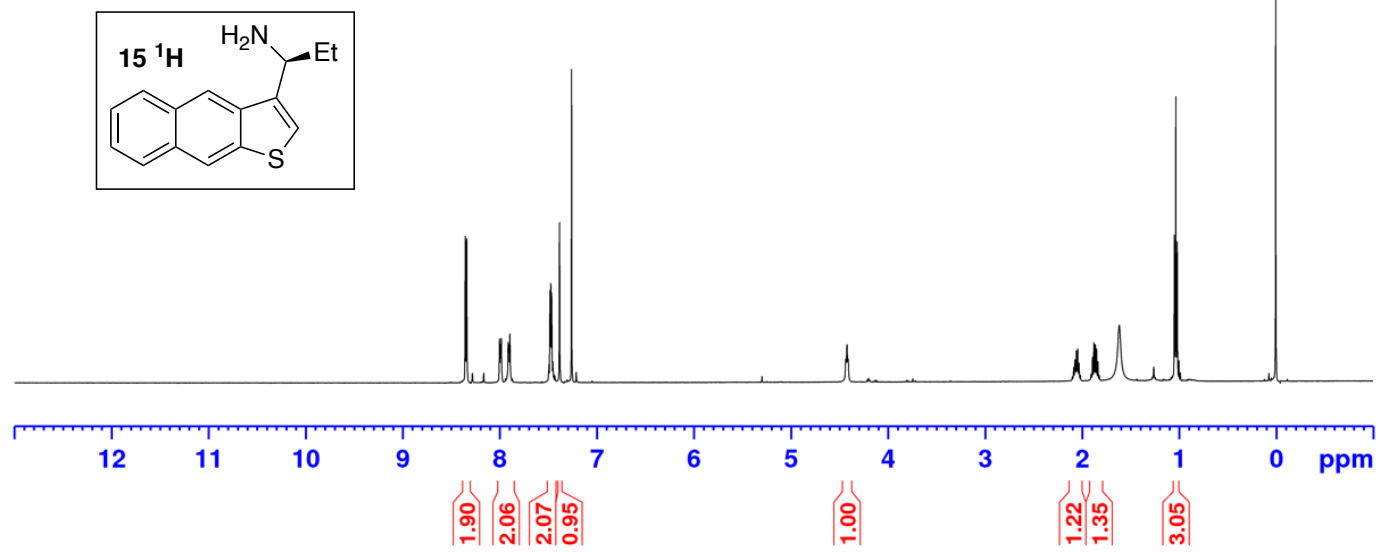

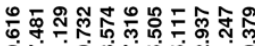

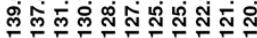

जiv
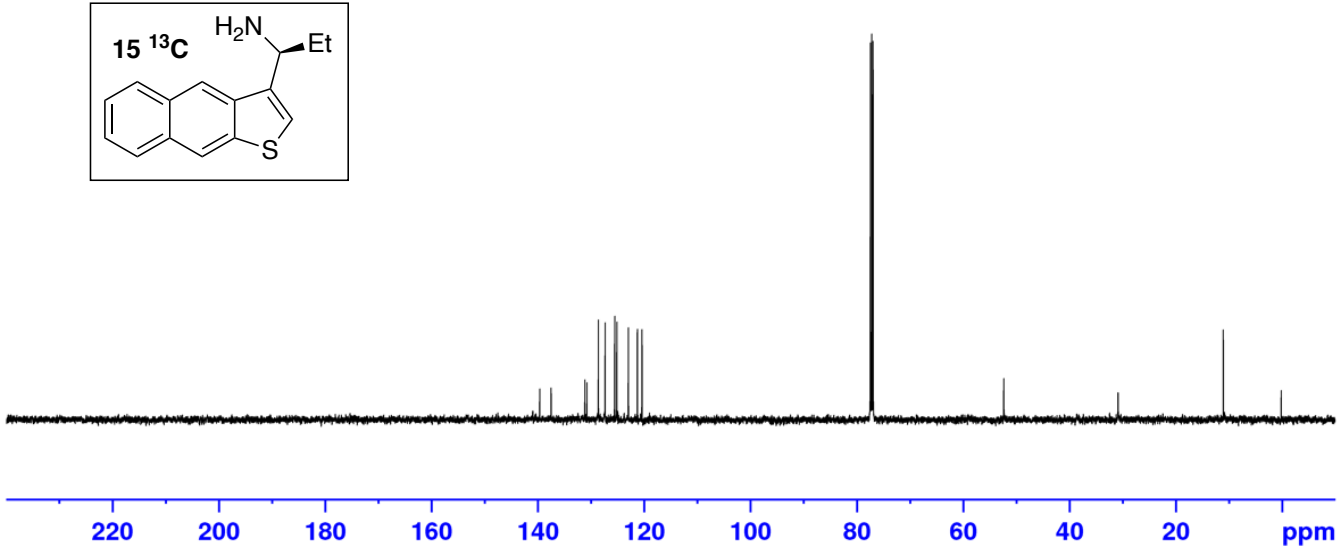